\title{
Multiscale Terrain Analysis of Multibeam Bathymetry Data for Habitat Mapping on the Continental Slope
}

\author{
MARGARET F. J. WILSON, BRIAN O'CONNELL, COLIN \\ BROWN, JANINE C. GUINAN, AND ANTHONY J. GREHAN \\ Department of Earth and Ocean Sciences, National University of Ireland, Galway
}

\begin{abstract}
Multibeam surveys can provide detailed bathymetry data for the continental slope from which quantitative descriptors of the seabed terrain (e.g., slope) may be obtained. We illustrate the value of these descriptors for benthic habitat mapping, and highlight the advantages of multiscale analysis. We examine the application of these descriptors as predictor variables for species distribution models, which are particularly valuable in the deep sea where opportunities to directly survey the benthic fauna remain limited. Our initial models are encouraging and suggest that wider adoption of these methods may assist the delivery of ecologically relevant information to marine resource managers.
\end{abstract}

Keywords Multibeam bathymetry, terrain analysis, scale, habitat suitability modelling, continental slope

\section{Introduction}

Ecologists involved in terrestrial habitat and vegetation mapping studies have developed their science against a backdrop of improving topographic information. Visualization and analysis tools too have advanced and simple contour maps have now largely given way to Digital Terrain Models (DTM), which may be readily analyzed in a geographic information system (GIS) environment. Parameters derived from these DTMs have been used in numerous studies to classify habitat and to predict soil, vegetation cover, and species distributions at a variety of scales (Franklin 1995; Franklin et al. 2000; Hirzel 2001; Schmidt and Hewitt 2004; Wu and Smeins 2000).

Until recently, no detailed terrain data were available for the marine environment. Historically, bathymetry data were acquired primarily for navigation purposes and, while certain coastal areas may be reasonably well charted, vast areas of the deep sea remain largely unexplored. Even when studies such as Le Danois (1948) provided evidence that the deep sea supported a variety of benthic fauna and began describing its regional distribution, attempts at habitat mapping were limited without this baseline bathymetry information. With only a basic knowledge of seafloor bathymetry coupled with imprecise position information for biological samples, studies of the deep-sea benthic fauna tended to focus

Received 21 June 2006; accepted 4 November 2006.

Address correspondence to Margaret F. J. Wilson, Geological Survey of Norway, 7491 Trondheim, Norway. E-mail: margaret.wilson@ngu.no 
on ecology (e.g., Billett 1991) biodiversity (e.g., Rex et al. 1997), or biogeography of certain species (e.g., Riemann-Zürneck 1986) without any explicit link to the seabed terrain.

With the advent of multibeam technology (Kenny et al. 2003), marine benthic habitat mapping has entered a new era. Ship borne multibeam bathymetry surveys, such as those conducted under the Irish National Seabed Survey (INSS) (GOTECH 2002), have provided spectacular detail of deep sea terrain revealing numerous previously unrecognized features. Multibeam surveys provide the detailed bathymetry data necessary for the production of submarine DTMs which, unlike traditional charting formats (contours, soundings), lend themselves well to terrain analysis. Multibeam data have proven their value for habitat mapping (Kostylev et al. 2001; Parnum et al. 2004; Van De Beuque et al. 1999) and studies of the distribution of benthic fauna (Kostylev et al. 2003). Shipborne multibeam data are also being complemented by Remotely Operated Vehicle (ROV)-based multibeam surveys, which provide a means to obtain submeter level bathymetry in deeper waters (e.g., Wilson 2006).

With the advent of ROV-based video surveys of the benthic fauna, we can now also obtain precisely georeferenced visual data on the distribution of at least the larger animals colonizing the seafloor - the benthic megafauna. These are generally visible in video data and, thanks to precise position information from accurate underwater positioning systems, we know exactly the location for each observation. Now that biological information can be directly georeferenced to the underlying seabed terrain, we can begin to characterize the distribution of the fauna in relation to this terrain and develop predictive habitat and species distribution models. Renewed commercial interest in deep sea resources, coupled with the need for sustainable management, demands habitat information and predictive models may be the only practical way to address this demand in the deep sea.

While the distribution of benthic fauna may be controlled by a combination of environmental and biological factors, it is generally recognized that many animals show a particular affinity for certain types of terrain (e.g., Džeroski and Drumm 2003; Roberts et al. 2003; Wilbur 2000), which provide the physical habitat or structure that is directly or indirectly suited to their mode of living. Characterization of the seabed in terms of terrain parameters such as slope, aspect, or curvature may therefore offer a valuable tool for delineating regions of the continental slope that are likely to support particular fauna and thereby provide a distinct habitat. Recent work in shallower water has indicated the potential for these types of techniques (Bekkby et al. 2002; Dartnell and Gardner 2004; Lundblad et al. 2006), but there has been little work in deeper waters beyond the continental shelf. It is perhaps in the relatively inaccessible deep sea, where the expense of direct surveying makes ground-truth observations scarce, that techniques such as terrain modeling based on multibeam data can make a significant contribution to the prediction of benthic habitat.

One important issue that should be addressed by any attempt at habitat mapping, observed or predicted, is that of spatial scale. With seabed habitats and benthic fauna spanning a continuum of scales this is not an easy challenge to meet. Scale is especially important in relation to terrain analysis, since both the initial DTM resolution and the analysis scale will influence the results. For habitat mapping it is important to try and match the data and analysis scales to those relevant to habitat size and the fauna themselves. Previous investigations of deep-sea habitat using video (e.g., Klages et al. 2004) have indicated that distribution of fauna exhibits patterns of variability on spatial scales smaller than the resolution of ship-borne multibeam at continental slope depths. However, these investigations have also revealed that certain fauna (e.g., cold water corals) exhibit tendencies to associate with larger scale features of the terrain such as carbonate mounds (De Mol et al. 2002). This suggests that larger-scale features may indeed be important 
contributors to the distribution of some fauna. In practice, for animals exhibiting a preference for particular types of terrain it is likely that a combination of large- and small-scale features contribute to their chosen habitat. We investigate the interaction of spatial scales with reference to a case study area in this paper. Several technical approaches that inherently address issues of scale can be recognized, including multiscale GIS visualization and analysis (Wood 1999), fractal dimension (Wallace et al. 2004), and wavelet analysis (Csillag and Kabos 2002), each of which will be discussed further in this paper.

We begin with a review of methods for terrain analysis using deep-sea multibeam data. We then provide examples in a case study on the upper continental slope to the southwest of Ireland. Results of analyses at multiple scales are compared with each other and with video observations of benthic fauna with the aim of addressing the following questions:

- What terrain information can be derived from multibeam data?

- What are the benefits of analyzing data at multiple spatial scales?

- What spatial scales are most relevant to observed seabed habitat?

- Can the derived terrain variables be used to predict the distribution of benthic fauna?

\section{Bathymetric Terrain Analysis}

The terrain analyses focus on techniques that have most potential relevance to benthic habitat. Some of these methods are common to terrestrial applications; others have been modified for the marine environment. Terrain analysis methods can be grouped into four types of information (Figure 1):

- Slope,

- Orientation (aspect)

- Curvature and relative position of features

- Terrain variability

Each of these parameters potentially gives important information for the delineation and characterization of habitats and may be valuable inputs to predictive habitat modeling. In the following sections, we provide an overview of terrain analysis with notes on any

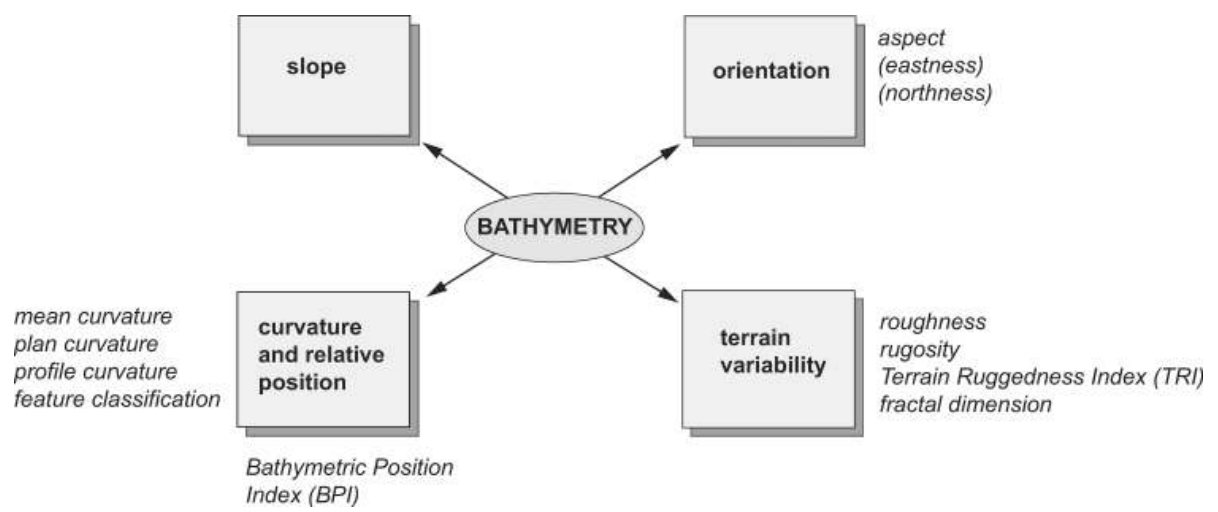

Figure 1. Major classes of terrain parameters that may be derived from bathymetry data. 
special considerations for deep-sea data and the relevance of each parameter to seabed habitat.

\section{GIS-Based Analyses}

By converting the bathymetric DTM to a raster grid, terrain analysis can be performed conveniently in a GIS environment. The raster resolution (also referred to by pixel or cell size) will be determined by the original multibeam data and the purpose for which the data are being prepared. One important point concerning multibeam data is that resolution and data density decrease with depth as a consequence of the beam geometry and lower multibeam frequencies used (Wilson 2006). Regardless of raster resolution, terrain analysis may be performed. However, it is important to note that the cell size, the analysis scale, and the choice of algorithm for the calculation of terrain parameters will all influence the results obtained (Albani et al. 2004). Although we have gridded our data at an optimal resolution for the study area, the majority of scientists and managers are restricted to working with agency-produced DTMs at a particular resolution. Unless DTMs at the highest meaningful resolution are available within the study area, the choice of algorithms and analysis scale will be restricted and so it is particularly important to understand the impact these will have on the analysis.

While certain terrain analyses may be performed on the basis of the raster grid and algebraic interactions between pixels, a more elegant and robust solution is to use some continuous representation of the DTM as a double-differentiable surface (e.g., Wood 1996). As we will demonstrate, this approach offers great flexibility in the choice of algorithms and the scales at which these analyses may be performed.

Using Evans' (1980) method, the DTM surface is approximated by a bivariate quadratic equation

$$
Z=a X^{2}+b Y^{2}+c X Y+d X+e Y+f
$$

where $Z$ is the height of the DTM surface and $X$ and $Y$ are the horizontal coordinates. The coefficients in Eq. (1) can be solved within a window using simple combinations of neighboring cells, the basis for terrain analysis in most commercial GIS, whether they use grid-based methods or a mathematical representation of the DTM. To perform terrain analysis across a variety of spatial scales, Wood (1996) solves this equation for an $n$ by $n$ matrix with a local coordinate system $(x, y, z)$ defined with the origin at the central pixel (Figure 2). These matrix algebra methods are implemented in Landserf software (Wood 2005) where the user may specify any odd number $(n)$ for the size of the square analysis window defining the portion of the raster DTM to be analyzed in relation to each central pixel in turn. Calculation of the various terrain parameters (e.g., slope, aspect) is achieved on the basis of a particular algorithm evaluated through solution of Eq. (1). Other surface representations are possible (e.g., Horn 1981; Travis et al. 1975; Zevenbergen and Thorne 1987). However, Evans' (1980) method is one of the most precise methods at least for first-order derivatives (Shary et al. 2002). While it might not be the best method for all applications, it performs well in the presence of elevation errors (Albani et al. 2004; Florinsky 1998).

Albani et al. (2004) present an analysis of the effect of scale on derived parameters for terrestrial data. They note how small-scale analyses (e.g., using a standard 3 by 3 window) are influenced by errors in the elevation surface or in the case of interpolated data prone to exhibit properties of the interpolation process. They also note how at large window sizes 


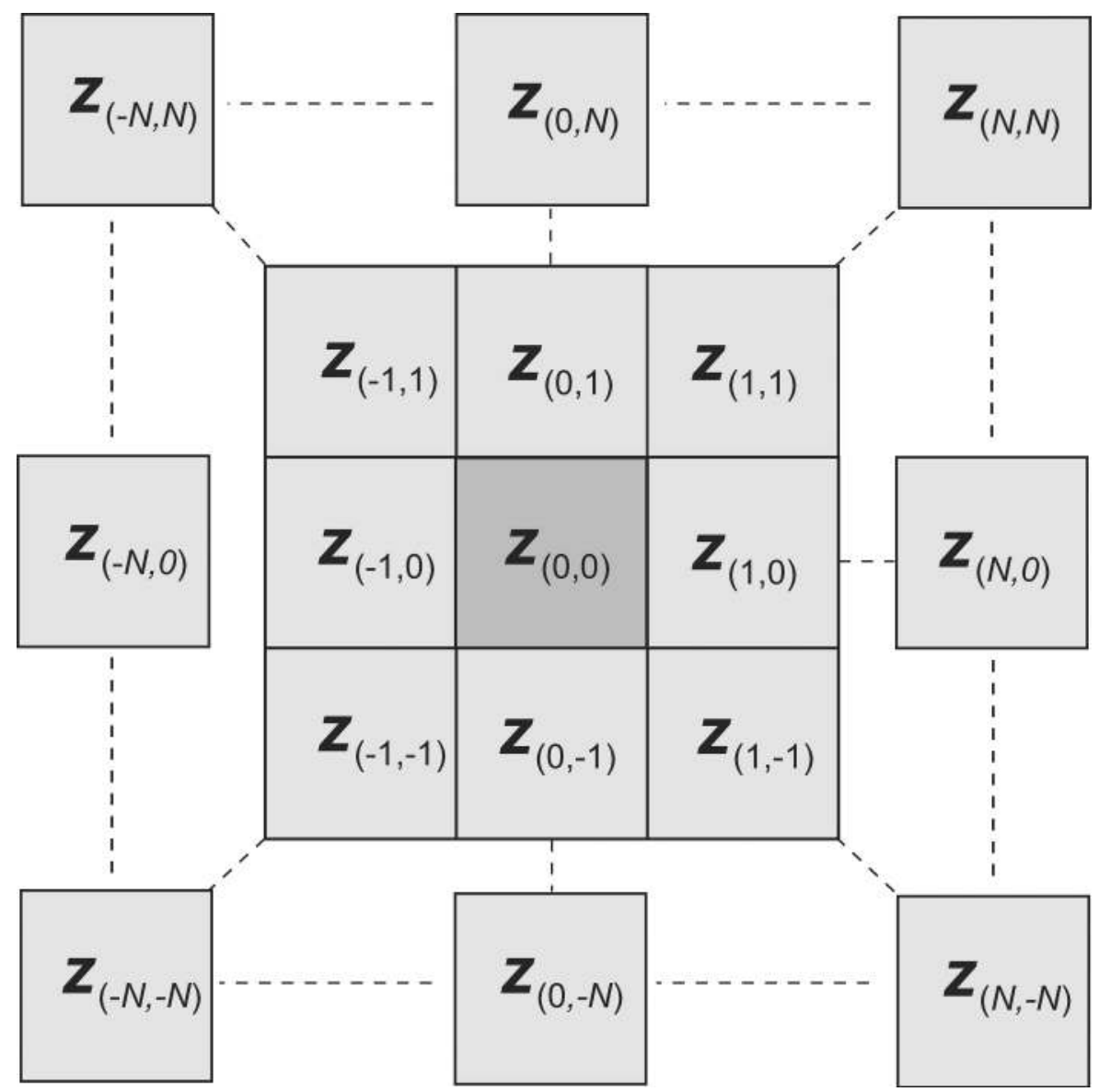

Figure 2. Raster grid, showing numbering system for cells in analysis window where $\mathrm{Z}$ is the value of the raster. The central cell is the origin of the local coordinate system $(x, y)$ and the positions relative to this are denoted by subscripts. To simplify notation we use $N=(n-1) / 2$ for any $n \times$ $n$ analysis window where $n$ may be any odd integer smaller than the number of cells shortest side of the raster. These are shown in full for a $3 \times 3$ window. Larger values of $n$ mean that more cells (larger area) are considered in the analysis.

the quadratic equation will be less likely to be a good descriptor of the terrain surface in the neighborhood of the central cell suggesting a potential upper limit in the useful range of analysis windows. Here we assess the choice of window sizes and their influence on derived terrain variables visually and with reference to habitat suitability models.

\section{Slope}

Slope is thought to be an important factor in determining benthic habitat and colonization in the deep sea at a variety of scales. Flat areas tend to exhibit different seabed facies and support communities that are different from those on steeply sloping areas (Dartnell and Gardner 2004; Iampietro et al. 2004; Lundblad et al. 2006). Slope may also contribute to current flow amplification (Mohn and Beckmann 2002), which has consequences for the 
supply of food to the benthic fauna. In relation to anthropogenic impact, we also note that slope may be a limiting factor in the use of particular fishing gears (Grehan et al. 2005a).

While slope analysis has been used in many marine based studies (e.g., Lundblad et al. 2006; Roberts et al. 2005; Whitmire et al. 2004), there has been little discussion in the associated literature of the algorithms used or the scale of analysis, which will have consequences for the slope values. Several comparative studies of methods for the calculation of slope have been reported for terrestrial DTMs (e.g., Florinsky 1998; Jones 1998; Kienzle 2004; Warren et al. 2004; Zhang et al. 1999), each of which reports a value in the direction of steepest slope within the analysis window. Other techniques such as directional slope calculations (Jenness 2005), which calculate the slope in a given direction, may be preferred for selected applications. Wavelet methods offer a novel method for calculating multi-scale slopes and are included in this study for comparison.

Evans' (1980) methods are reviewed by Wood (1996) and implemented in the Landserf software (Wood 2005). To calculate slope (or other terrain parameter), an analysis window is effectively moved across the raster DTM surface such that each pixel in turn becomes the central pixel on which calculations are based. The resulting calculations are still reported at the original pixel size; it is merely the window size or ground area considered in the analysis which varies. This generalization allows the parameter to be analyzed at a range of scales (different values of $n \geq 3$ ) but also serves the function of overcoming short-wavelength noise in the data such as the line-associated artifacts that typically arise in multibeam data (Hughes Clarke 2003). In this case, the user will have to decide the trade off between the analysis scale and the sensitivity of their investigations to noise/artifacts.

Slope is calculated from Eq. (1):

$$
\frac{\partial Z}{\partial X}=S_{x}=2 a X+c Y+d \quad \text { and } \quad \frac{\partial Z}{\partial Y}=S_{y}=2 b Y+c X+e
$$

By adopting a local coordinate system with the origin at the central point of the analysis window $(x, y=0)$, the slope at the centre of the (moving) analysis window is:

$$
\text { slope }=\arctan \left(\sqrt{d^{2}+e^{2}}\right)
$$

\section{Orientation (Aspect)}

Aspect is important to benthic habitat because it reflects the orientation of the seabed at any given location. This orientation is particularly relevant to local and regional currents, especially for suspension feeding fauna that rely on these currents to supply their food (Gage and Tyler 1991). It provides information on the exposure of any given area to such water movements, which may be important in shaping habitat and colonization. Slope and aspect are intrinsically linked since slope reflects that change in elevation along the steepest incline within the analysis window, whichever direction that may face. Despite this link, aspect has not been as widely used in marine habitat-related studies as indices such as slope. This may be partly because for many areas little is known about the oceanography and circulation patterns which make aspect significant. Even observing, for instance, that certain fauna occur on north facing slopes we gain an insight into the distribution of fauna. Aspect calculations presented here are also based on Eq. (1) and calculated using Landserf. 
The solution is:

$$
\text { aspect }=\arctan \left(\frac{e}{d}\right)
$$

It computes the azimuthal direction of steepest slope through the points in the analysis window. In our experience, aspect calculations are particularly sensitive to any artifacts in the DTM so it is important that the analysis scale is selected appropriately.

Aspect is typically measured in degrees from north but presents a difficulty that values numerically distant may be oriented in the same general direction (e.g. $1^{\circ}$ and $359^{\circ}$ ). Several researchers (Hirzel et al. 2002; Patthey 2003) have found that for certain analyses it may be useful to split aspect into two components following conversion from degrees to radians.

$$
\begin{gathered}
\text { eastness }=\sin (\text { aspect }) \\
\text { northness }=\cos (\text { aspect })
\end{gathered}
$$

These indices of northness and eastness provide continuous measures $(-1$ to +1$)$ describing orientation.

\section{Curvature and Relative Position of Features}

Curvature and related measures that describe the relative position of terrain features are important to benthic habitat in terms of exposure to currents and may also be linked to the nature of the seabed. For instance certain fauna will tend to colonize elevated positions, whilst others prefer low lying, or flat areas. Multi-scale analysis allows us to further delineate between favorable and unfavorable habitat for any particular animal, since local and broader scale influences are likely to be important (Guisan and Thuiller 2005).

Surface curvature. Curvature is a second spatial derivative of the seabed terrain. It is one of the basic terrain parameters described by Evans (1980) and is commonly used in terrestrial terrain analysis. It has found detailed application in soil science and has been found to be important in the classification of landforms (Schmidt and Hewitt 2004; Shary et al. 2002). It helps to delimit regions of distinct habitat by identifying boundaries in the character of the terrain. The importance of analysis scale is highlighted by Schmidt and Hewitt (2004) who illustrate the significance of profile curvature, calculated at different scales, as a predictor of soil properties. Curvature seems to have been largely overlooked by most researchers studying submarine terrain, perhaps due in part to the confusing array of possible curvature calculations (Schmidt et al. 2003; Shary et al. 2002).

The two most frequently calculated forms are profile and plan curvature (Gallant and Wilson 2000). Profile curvature is the curvature of the surface in the steepest down-slope direction. It describes the rate of change of slope along a profile in the surface and may be useful to highlight convex and concave slopes across the DTM. Plan curvature is the curvature of a contour drawn through the central pixel. It describes the rate of change of aspect in plan across the surface and may be useful in defining ridges, valleys and slopes along the side of these features.

Based on Eq. (1), Wood (1996) defines profile curvature as:

$$
\operatorname{prof} c=\frac{-200\left(a d^{2}+b e^{2}+c d e\right)}{\left(e^{2}+d^{2}\right)\left(1+e^{2}+d^{2}\right)^{1.5}}
$$


and plan curvature is given by:

$$
\text { planc }=\frac{200\left(b d^{2}+a e^{2}-c d e\right)}{\left(e^{2}+d^{2}\right)^{1.5}}
$$

Note that these terms are multiplied by 100 to express curvature as percent gradient per unit length (Albani et al. 2004).

These calculations depend on the slope (Schmidt et al. 2003; Shary et al. 2002) and are based on the curvature of a line formed by the intersection of a plane (defining the orientation of the curvature) and the DTM surface (Wood 1996). Maximum curvature (convexity), minimum curvature (concavity) are independent of slope and are based solely on surface geometry (Schmidt et al. 2003; Shary et al. 2002). They occur at regions where the slope is zero, where plan and profile curvature remain undefined and there is zero component to plan curvature.

Minimum and maximum curvature are calculated according to the formulae provided by Evans (1980)

$$
\begin{aligned}
& \operatorname{profc}_{\max }=-a-b+\sqrt{(a-b)^{2}+c^{2}} \\
& \operatorname{profc}_{\min }=-a-b-\sqrt{(a-b)^{2}+c^{2}}
\end{aligned}
$$

Mean curvature is simply the average of these two values, since plan curvature is zero at these points:

$$
\text { mean curvature }=\operatorname{prof}_{\text {mean }}=-a-b
$$

These and other curvature calculations are reviewed by Schmidt et al. (2003) who also clarify the confusion caused by different terminology.

Bathymetric Position Index. The bathymetric position index (BPI) is the marine version of the topographic position index (TPI) introduced by Weiss (2001) and has been applied to a number of benthic habitat studies in recent years (Iampietro and Kvitek 2002; Iampietro et al. 2004; Lundblad et al. 2006). The BPI value provides an indication of whether any particular pixel forms part of a positive (e.g., crest) or negative (e.g., trough) feature of the surrounding terrain. The calculation is a raster-grid based method rather than one based on quadratic representation of the DTM surface. Nevertheless, since the BPI is based on the variation among cells within a specified radius or annulus, it may be calculated at a variety of user-defined scales so as to capture local- and broad-scale variations in bathymetric position. Our calculations were performed using ArcInfo's raster calculator using a slightly modified version of the formula used by Lundblad et al. (2006), without integer rounding.

$$
\mathrm{BPI}=Z_{\text {grid }}-\text { focalmean }\left(Z_{\text {grid }}, \text { circle }, r\right)
$$

where $Z_{\text {grid }}$ is the raster bathymetry grid. The 'focalmean' calculation reports the mean of the raster values within the circle of radius $r$. We follow Lundblad's notation indicating the scale of the BPI calculation which is denoted as BPI/scalefactor $\rangle$, where

$$
\text { scalefactor }=r \times\left(\text { cell size of } Z_{\text {grid }}\right)
$$

Lundblad et al. (2006) also present an alternative calculation based on an annulus rather than a circle. Visually we found little difference in the results between the two methods. For 
low-lying areas we find it preferable to keep a full floating point grid of values, particularly for further analysis such as habitat suitability modeling.

Feature extraction. Eq. (1) can also be written in the form of the general conic (Wood 1996)

$$
a X^{2}+2\left(\frac{c}{2}\right) X Y+b Y^{2}+2\left(\frac{d}{2}\right) Y+2\left(\frac{e}{2}\right) Y+(f-z)
$$

or as

$$
a X^{2}+2 h X Y+b Y^{2}+2 j Y+2 k Y+m
$$

Consideration of the quadratic surface as a conic section allows morphometric features to be identified as peaks or pits (elliptic), ridges or channels (parabolic), passes (hyperbolic), or the special case of a planar surface (Wood 1996; Wood 1998). The basic form of the surface is defined by the values of the coefficients $a, b$ and $h$ and further distinctions between feature classes are detailed by Wood (1996). Feature extraction may be performed at multiple scales using the methods outlined in Wood (1998), which are implemented in Landserf. These techniques have been developed to include fuzzy classification across a range of scales (Fisher et al. 2004). Membership of any class at a particular location is given as a weighted average of the Boolean memberships of that class over the scales considered. In this study, we consider these methods implemented in Landserf in order to get an idea if this analysis is useful for the delineation of benthic habitats.

Other methods for feature extraction have also been proposed, for example on the basis of terrain (bathymetric) position, slope and rugosity (Lundblad et al. 2006); or using a combination of slope, curvature and terrain position (Schmidt and Hewitt 2004) who also employ fuzzy classification.

\section{Terrain Variability}

The variability or complexity of the terrain has been linked to the distribution of fauna by several researchers (Beck 2000; Kostylev et al. 2005), and, at the appropriate scales, may be a key parameter in distinguishing suitable habitat for particular fauna. At a local level, certain species require a complex habitat with a strong structural component (e.g., rocky outcrops) whilst others tend to occupy flat terrain typical of soft sediment areas. At a broader scale, terrain variability indices reflect variations related to seabed morphology.

Terrain Ruggedness Index. The Terrain Ruggedness Index (TRI) was adapted by Valentine et al. (2004) for bathymetry data from the method presented by Riley et al. (1999) for terrestrial ruggedness. The TRI value is a measure of the local variation in seabed terrain about a central pixel. Since variations in the seabed terrain are associated with changes in habitat and colonization, they may be particularly relevant for habitat mapping studies. The TRI value is calculated by comparing a central pixel with its neighbors, taking the absolute values of the differences, and averaging the result.

Using the notation in Figure 2 for a $3 \times 3$ window we have:

$$
\operatorname{TRI}=\left(\begin{array}{l}
\left|z_{(-1,1)}-z_{(0,0)}\right|+\left|z_{(0,1)}-z_{(0.0)}\right|+\left|z_{(1,1)}-z_{(0,0)}\right|+\left|z_{(-1,0)}-z_{(0,0)}\right| \\
+\left|z_{(1,0)}-z_{(0,0)}\right|+\left|z_{(1,-1)}-z_{(0,0)}\right|+\left|z_{(0,-1)}-z_{(0,0)}\right|+\left|z_{(1,-1)}-z_{(0,0)}\right|
\end{array}\right) / 8
$$


Calculations were performed in ArcInfo using a macro developed by Valentine et al. (2004). Neighborhood mean filters may optionally be applied in ArcInfo to smooth the results. This index is conceptually similar to the Terrain Amplitude Index introduced by Díaz (1999), although there are differences in the computation methods.

It is possible to extend the technique to a multiscale version by applying the technique to DTM surfaces previously generalized to other analysis scales using the methods of Wood (1996), or by averaging the results through a neighborhood filter in ArcGIS, an approach to multiscale analysis taken by (Bekkby et al. 2005). Alternatively, we may extend Valentine's (2004) definition to a multiscale TRI equation that allows computation using an $n \times n$ window where $N=\frac{(n-1)}{2}$ :

$$
\operatorname{TRI}(n)=\frac{\sum_{i=-N}^{N} \sum_{j=-N}^{N}\left|Z_{i j}-Z_{00}\right|}{\left(n^{2}-1\right)}
$$

This calculation could be implemented in GIS using an extended macro; alternatively it may serve as a basis for other computation methods such as wavelet analysis.

Rugosity. The rugosity (Jenness 2002) has been used by a number of marine habitat studies to date (Iampietro et al. 2004; Lundblad et al. 2006). This is the ratio of the surface area to the planar area across the neighborhood of our central pixel.

$$
\text { rugosity }=\frac{\text { surface area of } 3 \times 3 \text { neighbourhood }}{\text { planar area of } 3 \times 3 \text { neighbourhood }}
$$

By this method flat areas will have a rugosity value near to 1 , while high relief areas will exhibit higher values of rugosity. Calculations were performed in ArcView 3.3 using the Surface Areas and Elevation Grids extension (Jenness 2002). Using this extension, the analysis is limited to a single scale and whether or not it captures rugosity at a level relevant to observed habitat is therefore sensitive to the initial raster resolution.

As with TRI, we may extend this technique to multiscale analysis using a generalized surface or by implementing a multiscale version of the rugosity calculation in our GIS using an $n \times n$ window, extending the methods described by Jenness (2002).

Roughness. Dartnell (2000) used the focal statistics routines available in ArcInfo to compute the maximum or minimum bathymetry value within a user defined $n \times n$ rectangular neighborhood (Figure 2) surrounding the central pixel. The roughness $(R)$ is then calculated as the difference between these maximum and minimum values.

$$
\begin{aligned}
B_{\max }(n) & =\text { maximum } Z \text { in } n \times n \text { window } \\
B_{\min }(n) & =\text { minimum } Z \text { in } n \times n \text { window } \\
R(n) & =B_{\max }-B_{\min }
\end{aligned}
$$

Fractal dimension. The fractal concept (Mandelbrot 1983) is often referred to as a measure of the surface complexity, which has been linked to habitat structure and biodiversity on rocky shores (Commito and Rusignuolo 2000; Kostylev et al. 2005). Fractal approaches have been adopted in the study of tropical coral reefs (Basillais 1997; Bradbury and Reichelt 1983; Mark 1984); however, these tend to focus on the coral structures themselves rather than the underlying seabed terrain. Simulated fractal surfaces have been used as models in ecological studies (Keitt 2000; With and King 1997) and to assist in the development of underwater technology (Riordan et al. 2005). 
Real landscapes typically exhibit fractal behavior within a local area. Topography can generally be considered self-similar in the two horizontal directions and self-affine in cross-section (Turcotte 1992). Following consideration of various topographic surfaces, Herzfeld and Overbeck (1999), in one of the few published studies of fractals in relation to seafloor bathymetry, conclude: "It is heuristically clear that seafloor or landscape topography is best described by fractal geometry, because of the different and increasingly detailed features appearing at increasing resolution."

There are a variety of methods available for the calculation of the fractal dimension $(D)$ of topography that will give a $D$ value between 2 (flat surface) and 3 (a space filling rough surface). The choice of method will be influenced by the data, study objective and ease of computation (Halley et al. 2004; Herzfeld and Overbeck 1999). One problem highlighted by comparative studies is that different methods can produce different estimates of the fractal dimension for the same surface. Tate and Wood (2001) report how this has led some researchers to conclude that apparent variations in $D$ reported for real landscapes are due mostly to the variations in the calculation methods, rather than differences in the topography itself. However if a single method of calculation is employed to compare $D$ for different areas we should still gain a reasonable measure of the relative variation which is relevant to seabed habitat.

Landserf implements the variogram method (e.g., Mark and Aronson 1984), which we use for the analyses presented here. The variogram is calculated as:

$$
\gamma(h)=\frac{1}{2 n(h)} \sum_{i=1}^{n} \sum_{j=1}^{n}\left(z_{i}-z_{j}\right)^{2}
$$

where $h$ is the lag between measured cells and $n$ is the number of pairs considered. Computation of $D$ is achieved through a plot of the log of variance against the log of lag, typically referred to simply as the log-log variogram. This method has been found the most applicable for multibeam bathymetry data (Herzfeld and Overbeck 1999). The value computed as part of the standard statistics in Landserf is a global measure of $D$ across the whole raster surface and so it can hide non-fractal behavior and spatial variation in roughness. It may, however, be useful as a general descriptor of the surface in a particular study area, and visual examination of the variogram (i.e., linearity of the log-log plot) will provide an indication of the extent to which the surface is truly fractal. An alternative approach in Landserf calculates $D$ within a moving window around each cell across the raster. This calculation has more relevance to habitat mapping since we gain an indication of how the surface roughness/complexity changes over the study area. $D$ may be calculated at different window sizes for $n \geq 9$.

For habitat mapping purposes, we are interested in determining whether the fractal dimension can offer a useful measure of the complexity of the seabed terrain with relevance for benthic habitat and the distribution of fauna. We are also interested in examining the effects of the data resolution and data smoothing on the fractal dimension calculations.

\section{Wavelet-Based Analyses}

An alternative to GIS-based terrain analysis is offered by methods based on the wavelet transform (Csillag and Kabos 2002; Keitt and Urban 2005; Kumar and Foufoula-Georgiou 1997; Saunders et al. 2005) that offers a potentially elegant means by which to perform 
multiscale analysis of seafloor bathymetry. Wavelet analysis has been likened to a mathematical microscope (Mallat 1999), in reference to the ability provided by shifting the wavelet (an oscillatory mathematical function) along a signal so that it can zoom in on different areas of the signal to quantify attributes of the signal at different scales. A small-scale wavelet is able to detect rapidly changing details, whereas a large-scale wavelet is able to detect slowly changing coarse features. In contrast to the Fourier Transform the wavelet transform is a local transform, which allows us to examine bathymetric data at different scales at a particular location.

Multiscale terrain analysis using wavelets exploits this multi-resolution property central to wavelet theory. During wavelet decomposition, the original signal (bathymetry) passes through two filters and emerges as two signals down-sampled in accordance with the Nyquist sampling theorem to retain all the information content of the signal while reducing the volume of data. This decomposition process can be iterated and eventually the original signal is broken down into many lower resolution components forming a wavelet decomposition tree. This process is called the Discrete Wavelet Transform (DWT). Bathymetric data can be decomposed to whatever scales are required (above the smallest scale present in the DTM) and in our examples follow the dyadic scale (Misiti et al. 2002).

One of the most important properties of wavelets is the vanishing moment (Mallat 1999). Shao and Ma (2003) use this property to construct derivatives of a signal at the $n$th order differentiation of a function. The $n$ th-order spatial derivatives of the bathymetric data can be obtained through a wavelet transform with a wavelet of $n$ vanishing moments. For example the first derivative of the bathymetry (i.e., slope) can be calculated with a Daubechies wavelet $\mathrm{db} 1$ or a Biorthogonal Bior1.5 wavelet, which have one vanishing moment, and aspect may be calculated from this. A second order derivative (i.e., curvature) can be found from a wavelet transform with a Daubechies db2 wavelet or a Biorthogonal Bior2.6 wavelet, which have 2 vanishing moments.

\section{Terrain Analysis of Multibeam Bathymetry Data in the Porcupine Seabight, SW Ireland}

The data are from the continental slope to the southwest of Ireland, on the eastern flank of the Porcupine Seabight. The region includes a region of small mounds and a large slope and channel feature spanning water depths from 300 to $500 \mathrm{~m}$ (Figure 3). The extent and ecological relevance of these mounds are reported by Wilson (2006).

The origin of the Macnas mounds is unknown; they are near circular with diameters of between 50 and $100 \mathrm{~m}$ rising only around $5 \mathrm{~m}$ above the ambient seabed. The study area is on a general west-facing slope between 300 and $500 \mathrm{~m}$ depth. Towards the north-west the gentle slope, where most of the mounds occur becomes a wider, steeper slope which opens into a channel. The area is of interest in terms of benthic habitat since it is noted as a hake (Merluccius merluccius) spawning ground. Video observations conducted using an ROV revealed that the mound and inter-mound areas contain distinct habitats hosting contrasting fauna. These observations suggest that the mounds are colonized by squat lobsters (Munida sp.) living on coral rubble, whilst the inter-mound areas consist of soft sediments, often colonized by anemones. Anecdotal information suggests that these mounds supported coral stands prior to the recent advent of industrial trawling in the area. No samples have been collected to confirm the age of the corals. 

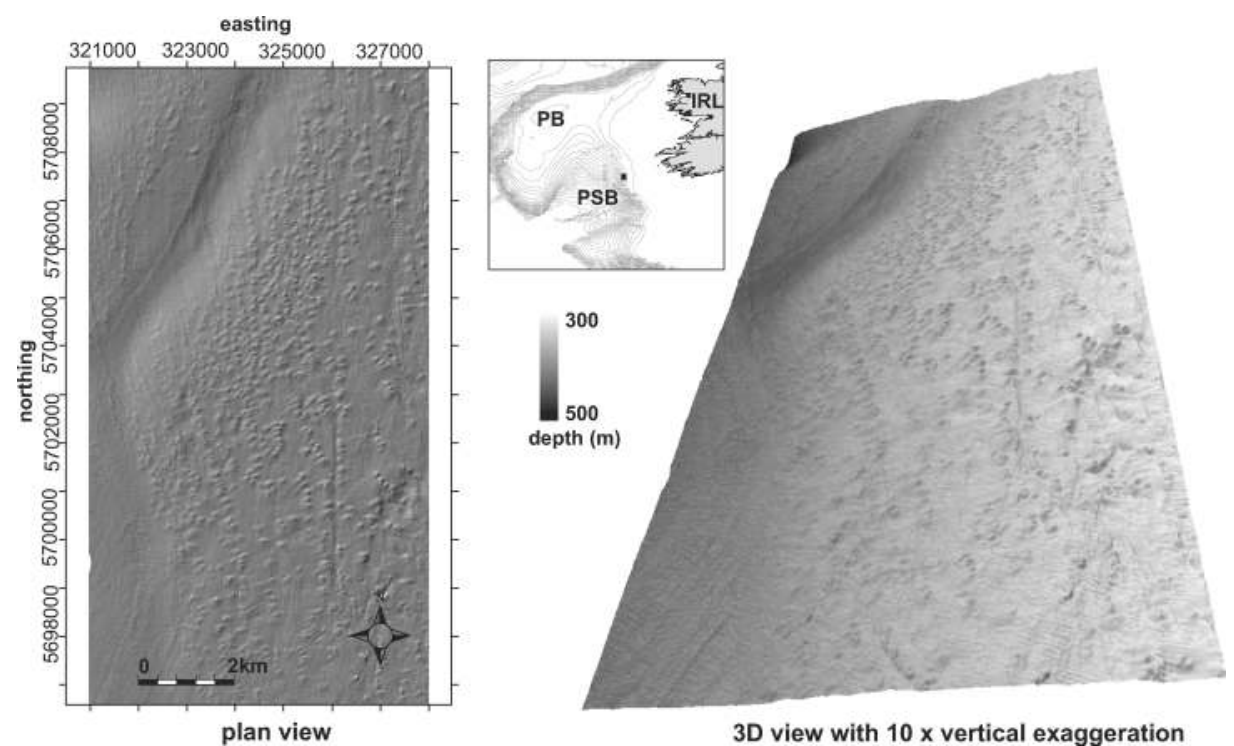

Figure 3. The Macnas Mounds study area in the Porcupine Seabight (PSB) to the SW of Ireland (IRL). The position of the Porcupine Bank (PB) is noted for reference. Projected coordinates UTM Zone $29 \mathrm{~N}$ (WGS84).

\section{Data Analysis}

Ship-borne multibeam data were acquired as part of the Irish National Seabed (Zone 3) Survey between 2000 and 2003. The multibeam system was the Kongsberg Simrad EM1002, which was hull mounted on the survey vessel S. V. Siren. The bathymetry data were collected in accordance with hydrographic standards using high-quality (DGPS) positioning, regular sound velocity profiles, and calibration offsets from a thorough patch-test. Further details on systems and data quality are supplied by GOTECH, (2002). The data for our study area were processed by the authors using CARIS HIPS 5.4 and used to produce a bathymetry grid with a cell size of $15 \mathrm{~m}$. Wavelet calculations were performed on ASCII gridded data and the gridded data were converted to GIS raster grids for the remaining terrain analysis. During data processing, we found the data to be of good quality, with sounding densities and depth accuracy well within hydrographic standards. Since our data were to be used for terrain analysis, however, we paid particular attention to the removal of line-to-line mismatches and spurious data towards the outer beams of the multibeam swath (for further details, see Wilson 2006). Such details would be evident in our $15 \mathrm{~m}$ grid and unduly influence the results of terrain analysis, although they would be unimportant for the production of regional bathymetric charts based on a larger bathymetric grid. Our processed bathymetric grid shows the seabed terrain in good detail with few of the artifacts common in multibeam data (Hughes Clarke 2003).

Video transect data acquired from ROV platforms flown close to the seabed provide a georeferenced visual record of the seabed habitat and fauna within the study area. The data were collected using the Bathysaurus ROV during June 2005 from the R. V. Celtic Explorer (Grehan et al. 2005b). Video data were acquired on mound and inter-mound areas, spaced as regularly as practical along a SE-NW transect through the northern part of the study area. Georeferenced images sampled from the video stream of a downward facing video 
camera were analyzed. These images are of sufficient resolution to confirm the occurrence of megafauna, which are our primary interest in terms of habitat mapping.

Terrain analysis was performed at a variety of scales on each dataset using the methods outlined above. For the GIS-based analyses, window sizes were selected using a subset of the Fibonacci sequence, which offers a convenient template for progressively increasing window sizes. The values $n=3,9,17,33,65$ offer a reasonable range of analysis scales, and using a $15 \mathrm{~m}$ grid, these correspond to ground distances of 45, 135, 225, 495, $975 \mathrm{~m}$ for each side of the analysis window. This is the range of meso-scale habitat features (Greene et al. 1999). In the case of the BPI calculations we used $r=3,9, \ldots 65$. The values of the various terrain variables were compared visually with video observations to assess their relevance in relation to observed seabed habitat, and to develop preliminary habitat models for the study area.

\section{Habitat Suitability Modeling}

Terrain variables are suited to use as indirect predictors of habitat for a given species. We present an example of their contribution to habitat suitability modeling using the Ecological Niche Factor Analysis (ENFA) technique (Hirzel et al. 2002) which relies on observations of a species presence, e.g., birds (Brotons et al. 2004), mammals (Dettki et al. 2003; Hirzel et al. 2002), corals (Leverette and Metaxas 2005), and plants (Engler et al. 2004; Zaniewski et al. 2002). In contrast to some more traditional techniques, the ENFA technique does not require absence data, which may be difficult, costly, or unreliable in the deep sea environment. For example video footage may miss the presence of fauna due to poor image quality caused by turbidity or excessive motion of the ROV; the image may be blurred due to technical problems such as poor focus or inadequate lighting; or the image may be acquired when the ROV is too far from the seabed to resolve the fauna. The models presented here are for the squat lobster (Munida sp.), which was one of the most abundant animals observed in the video footage.

ENFA uses a suite of predictor variables, eco-geographic variables (EGVs) for the study area and relates them to species observations in order to compute a habitat suitability (HS) model. The EGVs are first reduced to a few uncorrelated factors using eigensystem computation. These factors explain most of the information related to the distributions of the original EGVs and constitute the dimensions of the environmental space for the habitat suitability calculation. The most important feature of ENFA, and that which distinguishes it from other data reduction techniques such as principal components analysis, is that rather than just accounting for the variance among factors the ENFA factors have ecological relevance. The first factor accounts for all the marginality $(\mathrm{M})$ of the species, i.e., how the occupied cells differ from the average conditions of the study area; this is related to the mean of the distribution. The other factors account for successive amounts of specialization (S) which describe how selective the species is on the range of environmental conditions; this is related to the variance of the distribution. The contribution of individual EGVs to each factor gives an indication of their ecological relevance with respect to the species distribution. The amount of information explained by each factor in turn weights the EGV-space dimensions in which the habitat suitability is calculated. The models presented here were calculated using the harmonic mean algorithm (Hirzel and Arlettaz 2003). This is a distance-based algorithm that computes the harmonic mean of the distances to all observations in EGV-space. Effectively this method examines the influence field of each species observation in EGV-space such that when species observations are close together 
they serve to reinforce each other (Hirzel and Arlettaz 2003). Several other algorithms are available within BioMapper, and inter-algorithm performance is discussed further by Hirzel and Arlettaz (2003) and Wilson (2006).

Model performance was assessed using a $k$-fold cross validation procedure based on the method of Boyce et al. (2002), which is implemented in BioMapper 3.1. This method splits the species data into $k$ sets then uses all but one of these to calibrate the model and the remaining set to validate it. We used $k=7$ (Huberty's rule) and three bins of equal width $(0-33 ; 34-67 ; 68-100)$ in all cases to allow comparison between models. Examination of the area-adjusted frequency across the range of HS values provides a measure of model performance. The area-adjusted frequencies (AAFs) is the frequency of testing points lying within a bin, divided by the frequency of locations belonging to that bin across the study area (Hirzel and Arlettaz 2003). For a model with good predictive power, the AAF should be $<1$ for unsuitable habitat and $\gg 1$ (e.g., 10 or more) for suitable habitat. For a poor model, which predicts no better than by chance alone, AAF will be $\sim 1$ for all HS values. The maximum value of AAF at the highest HS bin reflects the deviation from randomness (Hirzel et al. 2006) with higher values indicative of a better model. This value can be used to compare models for the same species within the same area.

We produced and assessed the performance of several models; one using all available terrain variables (slope, aspect, etc., at the 5 scales) and others using only a subset of the variables (e.g., single scale, single parameter). Examination of the contribution of each parameter to the HS model allows us to gain an insight into the interaction of the different parameters and their importance in the prediction of the target fauna at different analysis scales.

\section{Results}

\section{Slope}

Two important features emerge from our multi-scale slope analyses (Figure 4). First, features with the largest slopes vary with the analysis scale; small window sizes effectively pick out the small scale variability around the mounds, larger scale analyses fail to do so and only highlight the larger scale slope towards the northwest of the study area. Second, the values of slope vary according to the size of the analysis window (Figure 5); with steeper slopes being identified over shorter distances considered in the smaller window sizes.

The values of slope will also vary with grid resolution since this sets the minimum scale length to perform a multiscale terrain analysis. We note however the potential for multi-scale analysis to help match the scale of analysis across different data resolutions obtained from different depths on the continental slope. For example, data from our study area may be gridded at $15 \mathrm{~m}$ owing to the spatially dense data produced by the multibeam system at this relatively shallow region of the slope. If the data had come from deeper on the slope (e.g., $1500 \mathrm{~m}$ ) our best grid resolution might be $75 \mathrm{~m}$. The results of the slope analysis simulating this effect are shown for the northern part of the study area (Figure 6).

\section{Aspect}

Aspect calculations effectively pick out the orientation of the terrain across the various analysis scales. There is a noticeable difference between the orientations of features resolved at the different scales (Figure 7). The largest scale $(n=33)$ only picks out the 

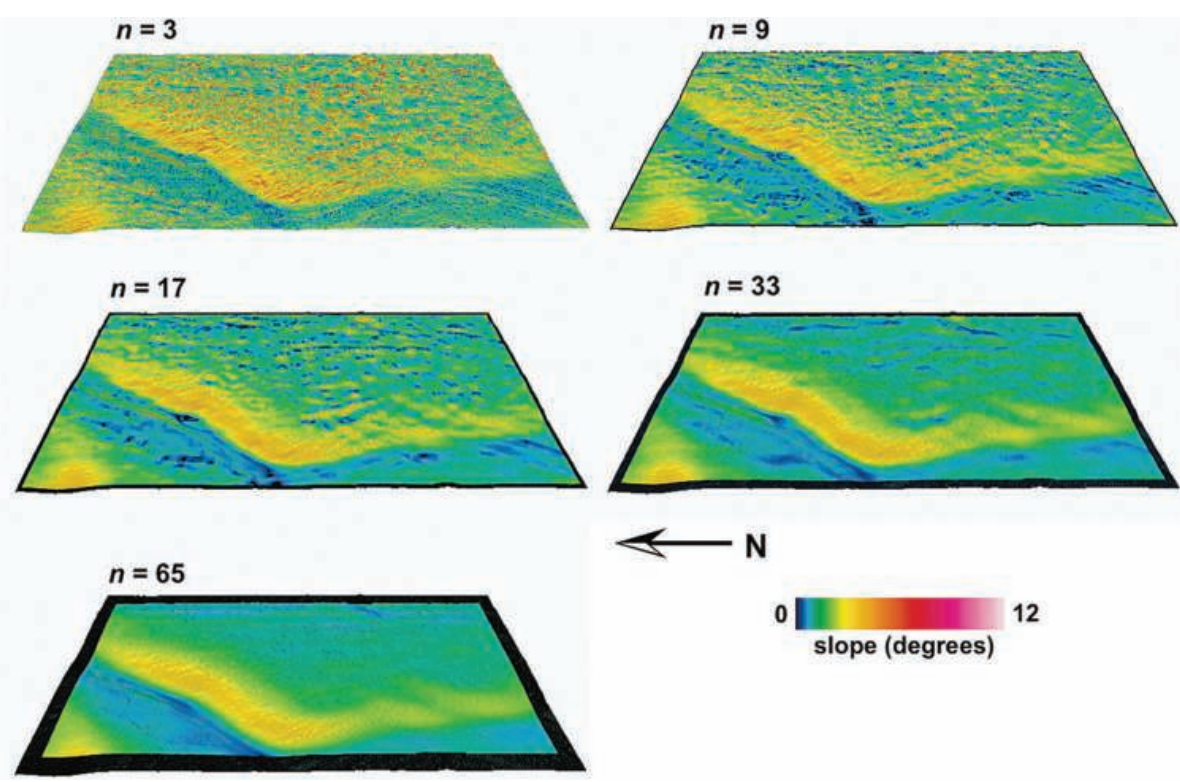

slope (degrees)

Figure 4. Variation in slope analysis and features delineated at different analysis scales. 3D views of Macnas Mounds area from west. Note that the multi-scale analyses results in no-data values towards the edge of the raster grid (black edge). The window size must always contain $n \times n$ cells so towards the edge of the raster there are insufficient cells to contribute to the analysis window, especially at large window sizes.

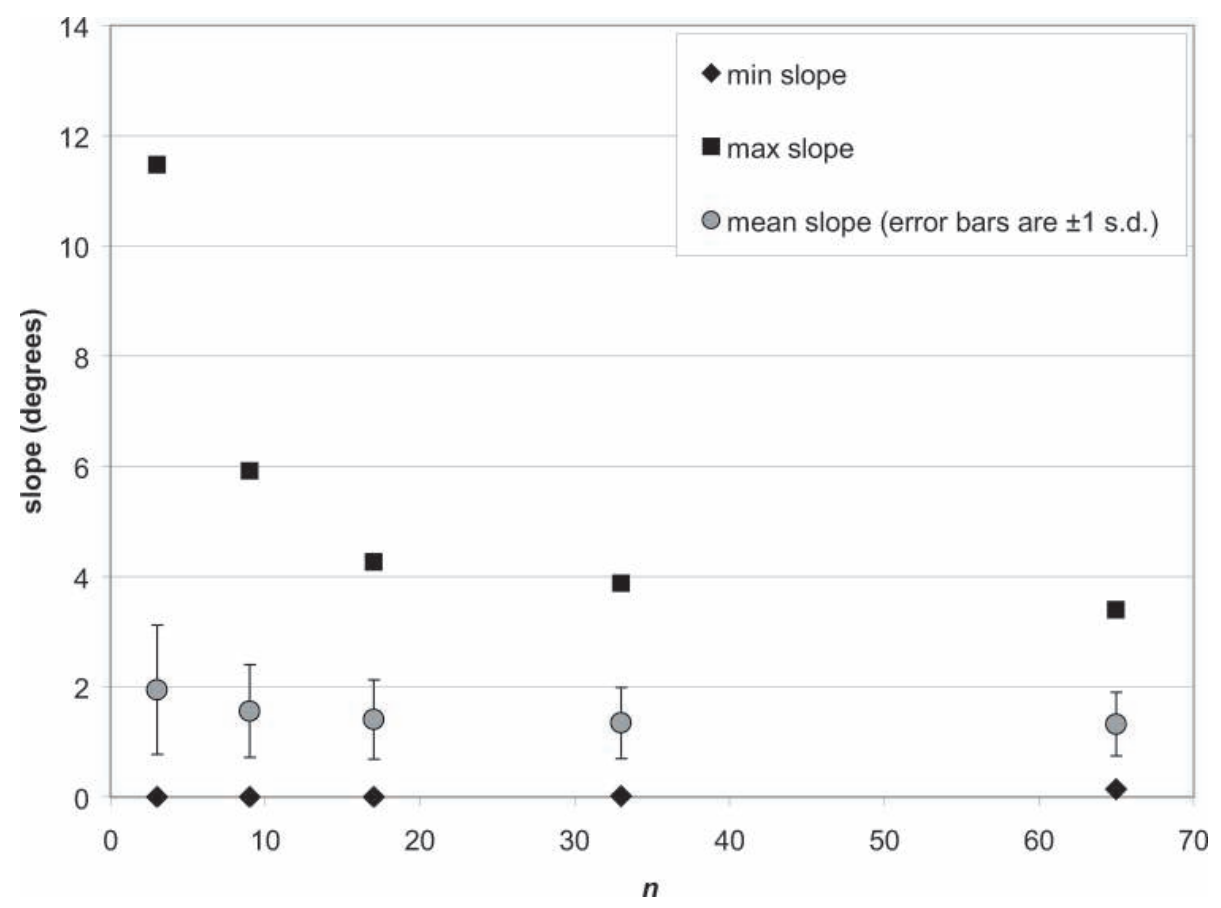

Figure 5. Variation in calculated values of slope at different analysis scales. 


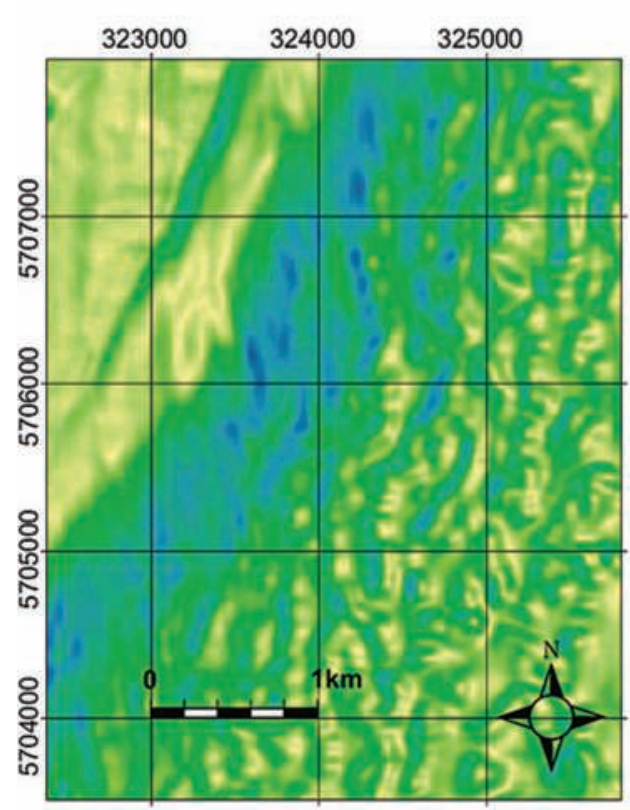

(a) $n=9$ from $15 \mathrm{~m}$ grid

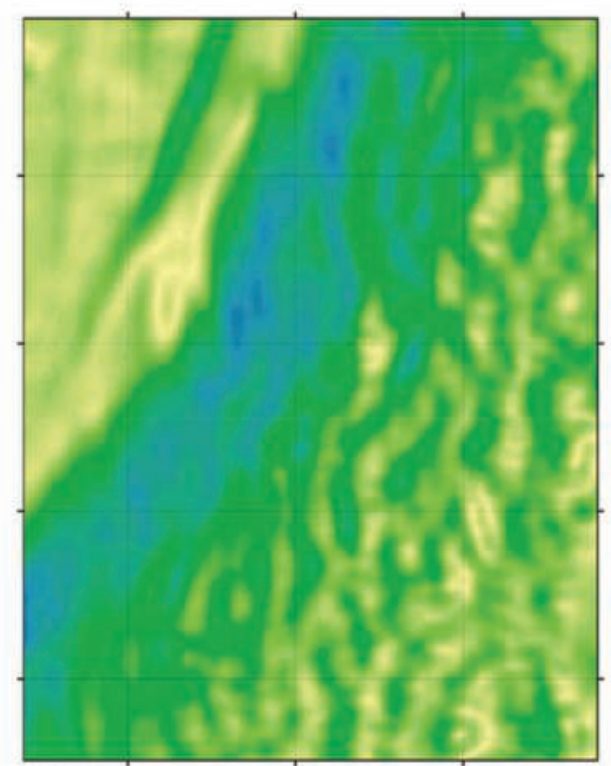

(c) $n=15$ from $15 \mathrm{~m}$ grid

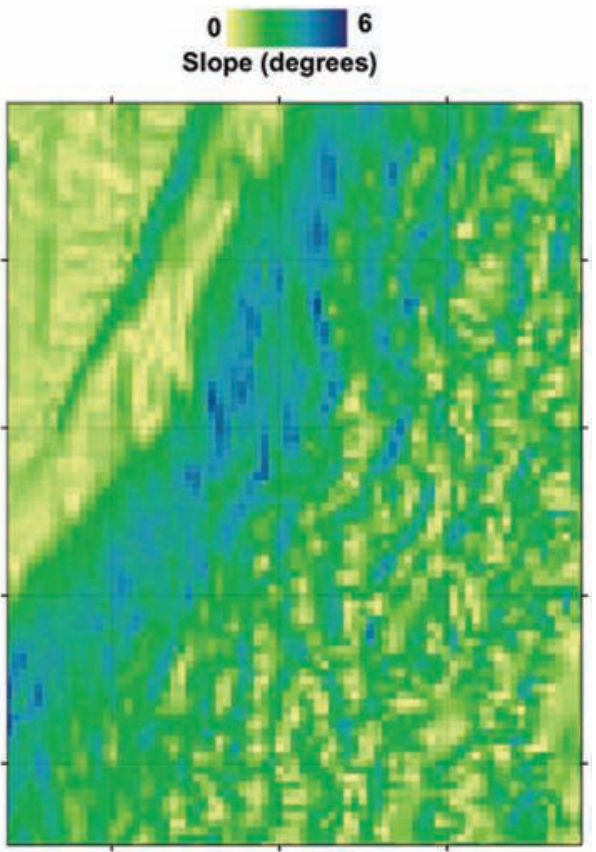

(b) $n=3$ from $45 \mathrm{~m}$ grid

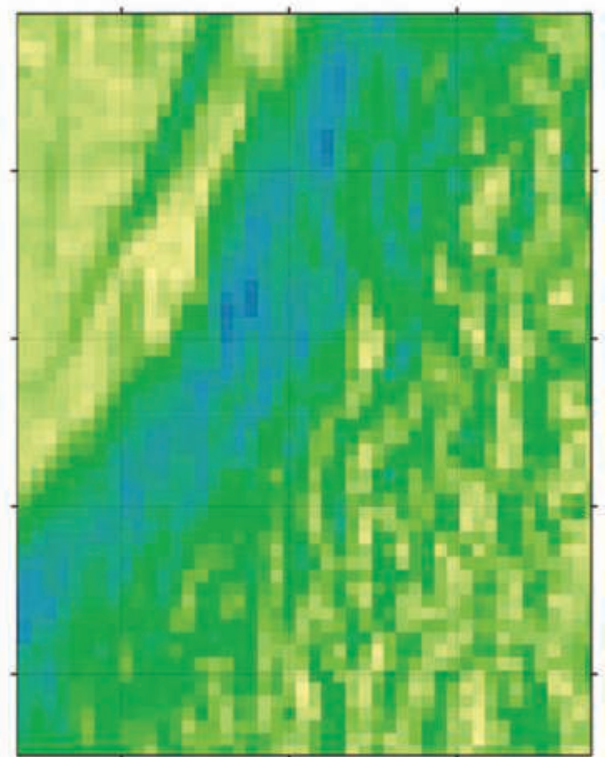

(d) $n=3$ from $75 \mathrm{~m}$ grid

Figure 6. Slope analyses performed over analysis window (a, b) $135 \times 135 \mathrm{~m}$ and (c, d) $225 \times$ $225 \mathrm{~m}$ to demonstrate matching the scale of analyses between using rasters with different grid resolutions. Projected coordinates UTM Zone 29 N (WGS84). 


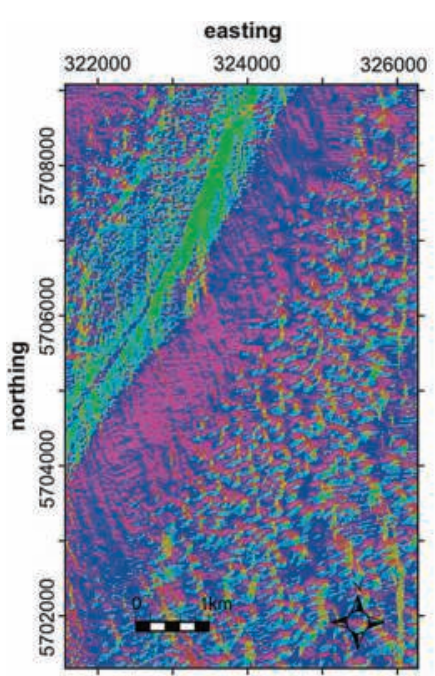

(a) $n=3$

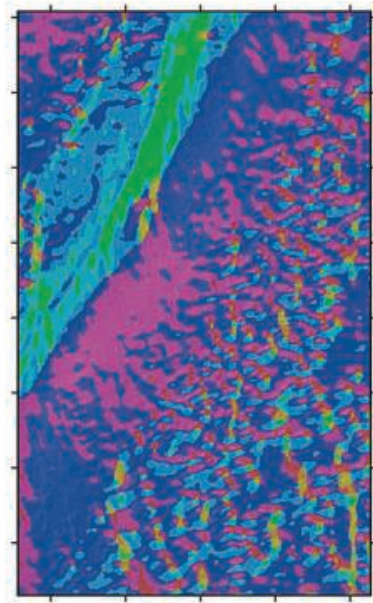

(b) $n=9$

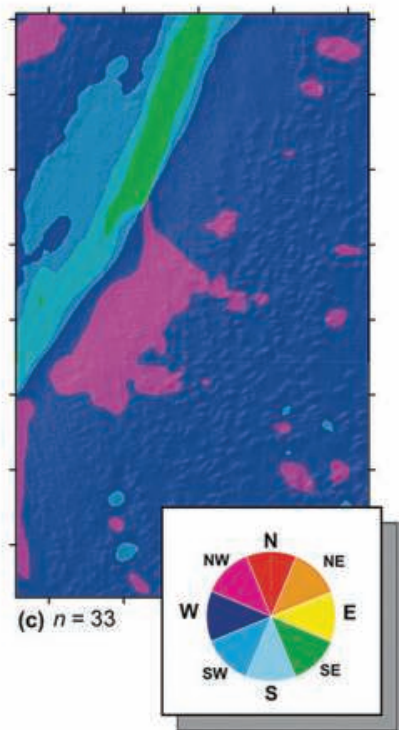

Figure 7. Aspect calculated at three different analysis scales from multibeam bathymetry of Macnas Mounds (15 m grid cell size). (a) aspect calculated using a local $(3 \times 3$ cell $=45 \times 45 \mathrm{~m})$ window which effectively picks out the small scale variations in orientation corresponding to the individual Macnas Mounds, (b) aspect calculated using a moderate $(9 \times 9$ cell $=135 \times 135 \mathrm{~m})$ window which still highlights some variation in orientation associated with the mounds (c) aspect calculated using a larger $(33 \times 33$ cell $=495 \times 495 \mathrm{~m})$ window which effectively highlights the large-scale changes in orientation across the area.

general orientation of the slope and the large channel whilst the individual mounds are not resolved.

The changing values obtained for terrain variables calculated at different analysis scales may be explored using interactive multiscale visualization tools (Wood 1999). Figure 8 highlights how a point on one side of a small-scale feature may exhibit quite different values for aspect across the range of analysis scales. At small scales it is facing generally east; however, at larger scales it is merely part of the general west-facing slope.

\section{Curvature}

Profile curvature (Figure 9a) and plan curvature (Figure 9b) separate curvature into two orthogonal components where the effects of gravitational process are either maximized (profile) or minimized (plan) (Wood 1996). This may be relevant to the distribution of sediment facies and sediment pathways. Profile curvature highlights the variation in curvature in the direction of the steepest gradient, effectively highlighting along-slope ridges and crests. Plan curvature shows the variation in curvature in the direction of the contours, thus highlighting the ridges and crests operating down-slope.

Maximum curvature (convexity) and minimum curvature (concavity) are defined for regions of zero gradient. Although they may be used independently, the mean curvature appears to provide a good general summary of the surface curvature and effectively delineates positive (e.g., mounds) and negative features of the terrain, making it similar 


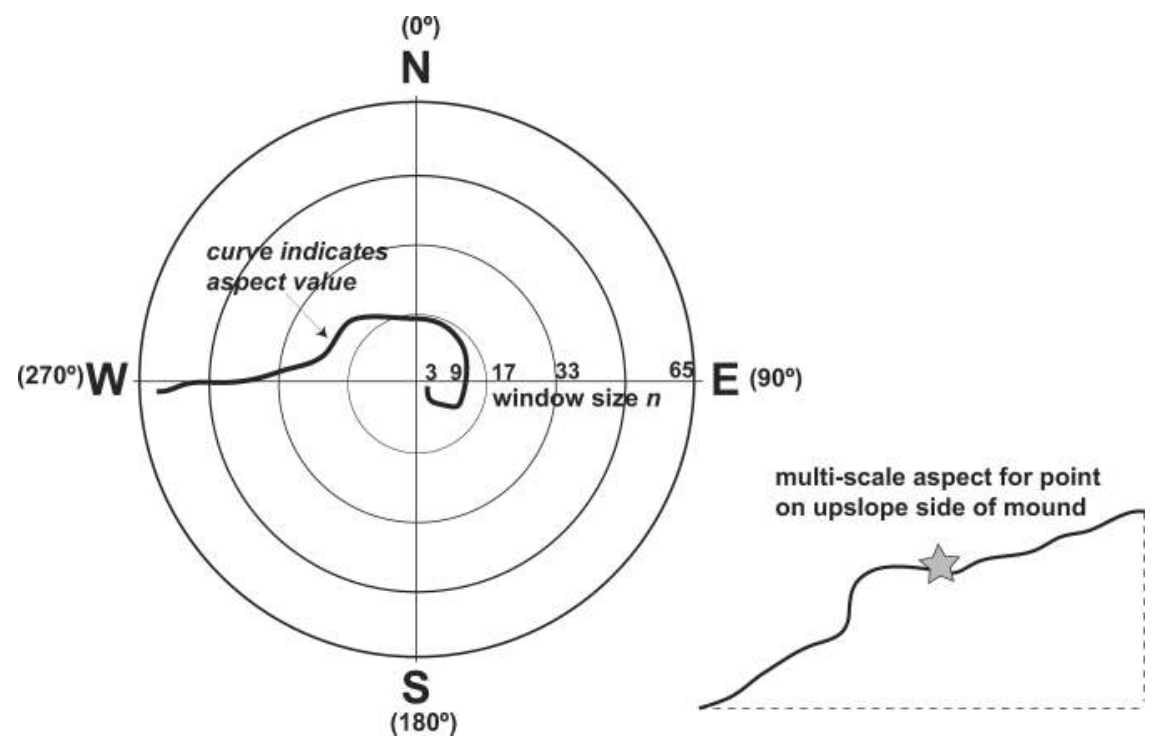

Figure 8. Multi-scale visualisation of aspect across different scales (redrawn from values given by multi-scale query tool in Landserf) from a point on the upslope side of the Macnas Mounds study area.

in effect to the BPI calculation. For this area we know from video observations that the mound summits are covered with coral rubble, while the inter-mound areas comprise soft sediments. By delineating these topographic highs and lows, we may therefore obtain a proxy to the sediment type that may be significant to our HS models, particularly where surficial geology data are unavailable, or to complement such data.
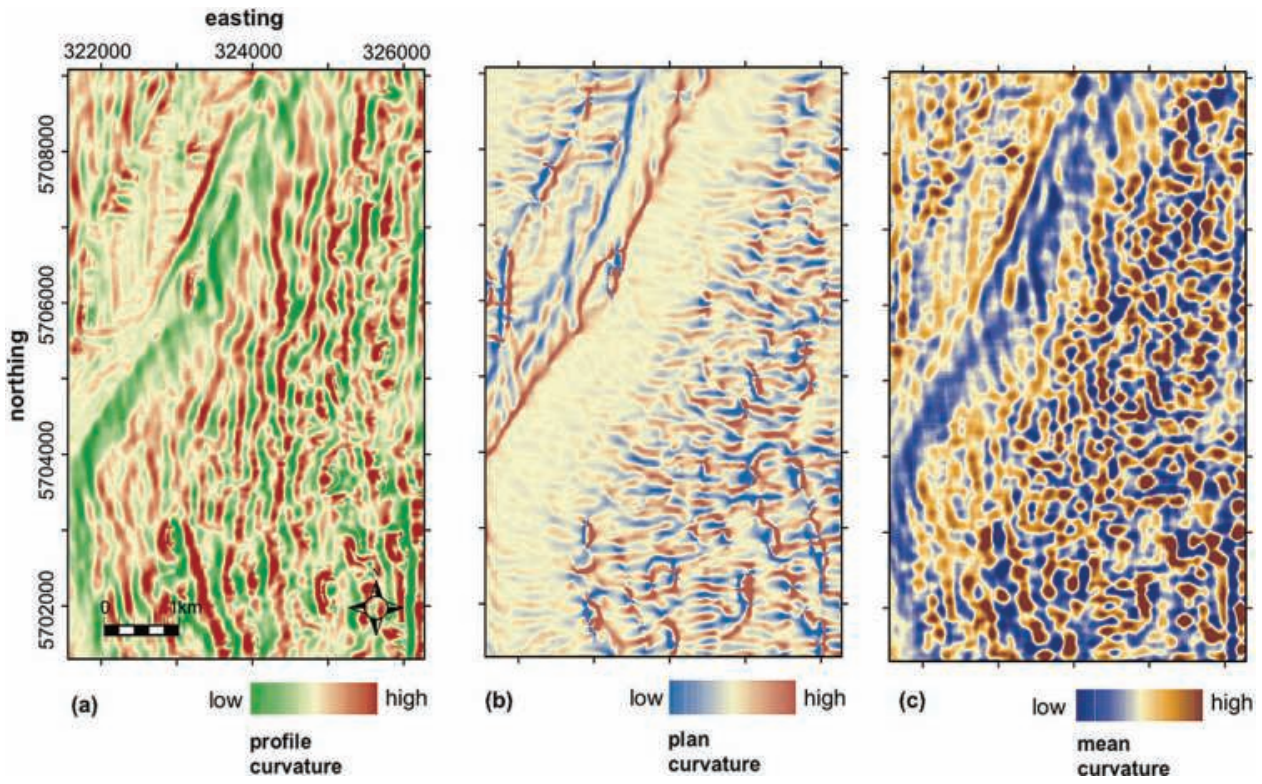

Figure 9. Examples of (a) profile (b) plan and (c) mean curvature calculated using a $17 \times 17$ analysis window for the Macnas Mounds. 


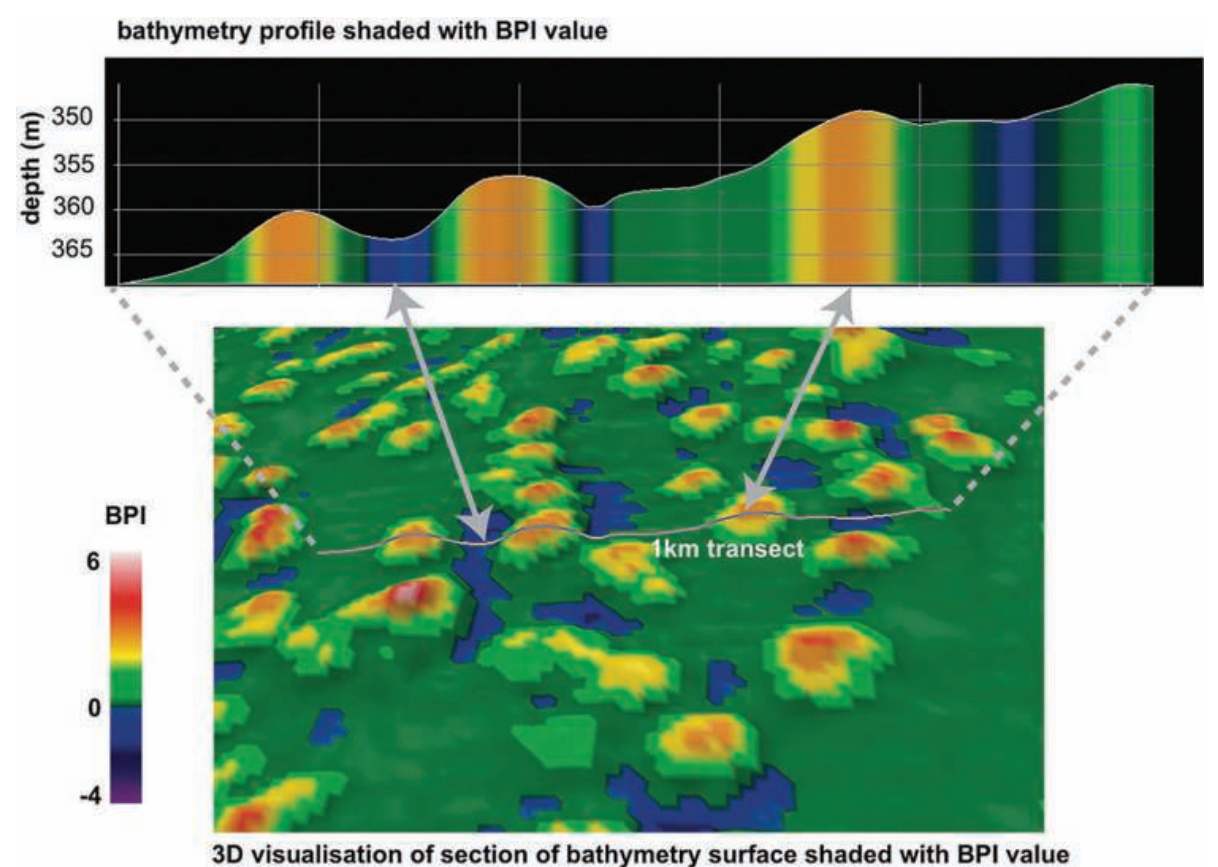

Figure 10. Bathymetric position index for $r=9(\mathrm{BPI}\langle 135\rangle)$ with 3 dimensional and profile view to illustrate how the algorithm effectively picks out positive and negative features of the terrain along a $1 \mathrm{~km}$ line transect.

Feature extraction. We extracted a range of terrain features using user-defined analysis scales and fuzzy feature classification. There are a number of limitations in using these features for HS modeling. Features calculated at a particular analysis scale produce a set of unique values corresponding to each type of feature (categorical data); they would therefore require further conversion to be suitable for use as continuous variables in our HS models. Since the features are merely based on curvature values, we found greater success by simply using the curvature values themselves rather than the classified features. Fuzzy feature classification produces continuous values ( 0 to 1$)$ across the raster surface indicating to what extent each pixel belongs to a particular feature class at all scales up to the user-defined window size. For this particular study area where the planar class was dominant, this meant large portions of the raster had near-zero values. This lack of variation is not well suited to HS modeling. Despite these limitations, we recognize that (fuzzy) feature classification shows promise for habitat mapping, particularly in areas of more rugged seabed terrain.

Bathymetric position index (BPI). The bathymetric position index effectively highlights positive and negative features of the terrain (Figure 10). This analysis performs well across the entire range of window scales and the use of floating-point rather than integer values ( $c f$. (Lundblad et al. 2006)) enhances use of this index in HS models.

\section{Terrain Variability}

Both the TRI and rugosity calculations are effective at highlighting small-scale variations in the terrain. The results tend to pick out the same features as the slope calculations with 


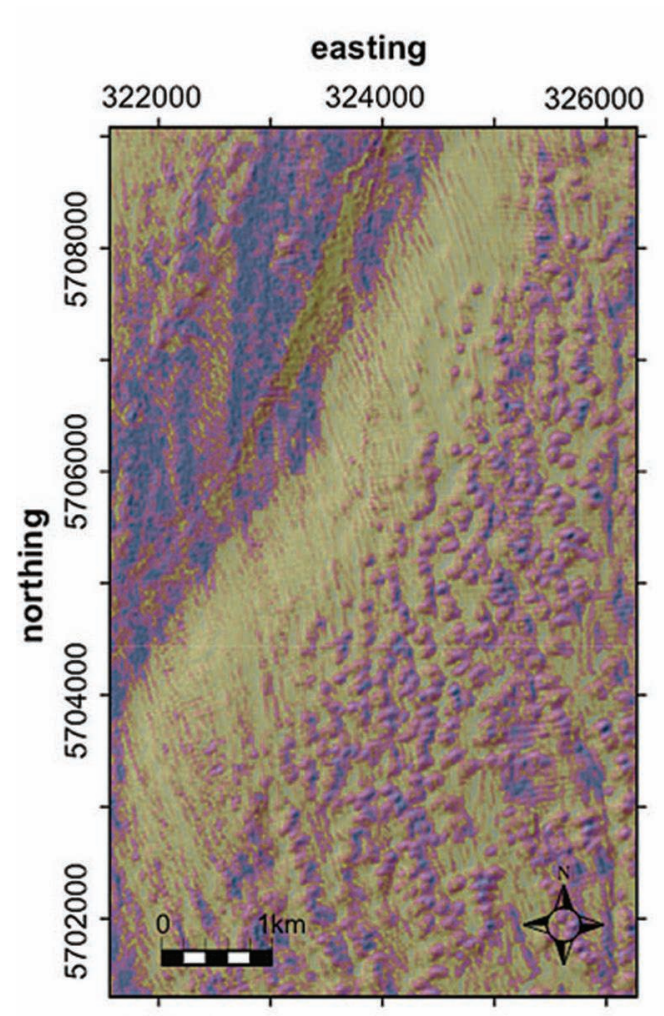

(a) $n=9$

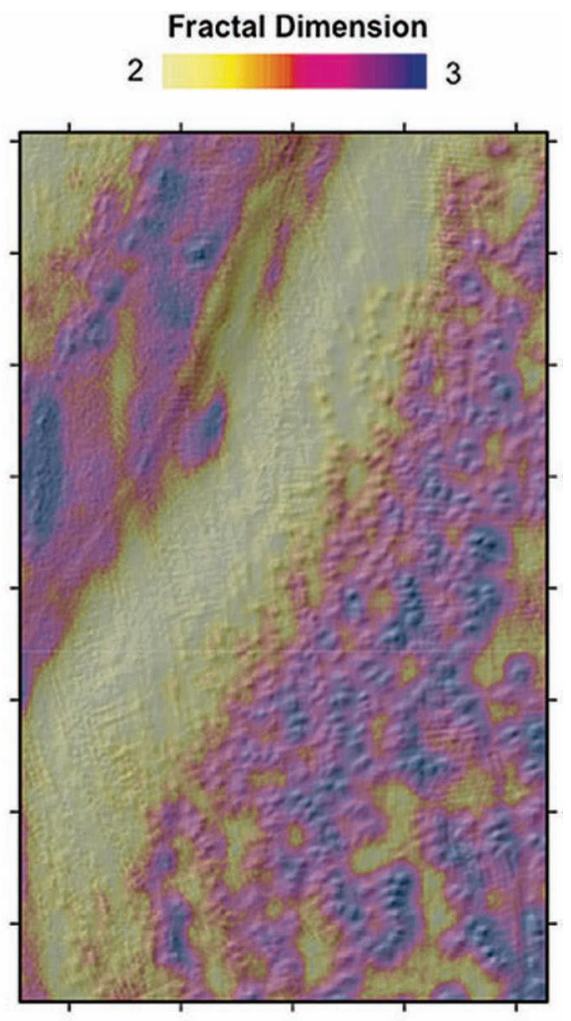

(b) $n=33$

Figure 11. Fractal dimension calculated at (a) $9 \times 9$ analysis window (b) $33 \times 33$ analysis window.

$n=3$. We tested the roughness index on several datasets using both a rectangular and a circular neighborhood. In both cases we found that while the method is effective at picking out features of the terrain at small window sizes, at larger window sizes the results exhibit artifacts of the analysis window shape rather than of the terrain itself.

Fractal dimension. The global fractal dimension for the study area is calculated to be 2.16, indicating that the region as a whole is relatively flat. Analysis of the variation in fractal dimension across the raster surface (Figure 11) reveals the surface complexity across the study area. Since smaller window sizes consider a smaller ground area they tend to capture the local variability of the terrain and report higher values for the fractal dimension. Larger window sizes generate lower values closer to those of the global fractal dimension; however, they still distinguish between areas where the surface is flat or complex (e.g., containing mounds).

We also examined the fractal dimension of the bathymetry surface (Figure 12) after smoothing through different size analysis windows. Research using one-dimensional fractal dimensions for the scaling of species distribution patterns (Hartley et al. 2004) has indicated at some intermediate spatial scale $D$ may exhibit a discontinuity marking the boundary between local- and broad-scale properties of the variable from which $D$ is being calculated.

We note two distinct portions of our curve indicating that there may be a break in detecting local and regional scale features at a value of $n \approx 21$. This coincides with our observations of the terrain features highlighted by terrain analyses at scales above $(n=$ 


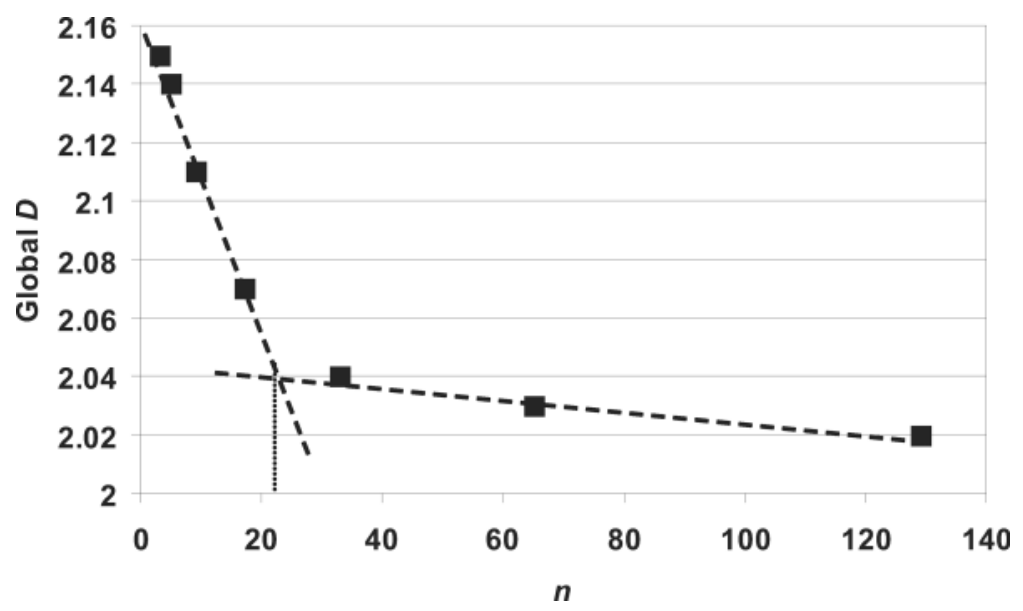

Figure 12. Global fractal dimension for bathymetry surfaces generalized 'smoothed' through analysis window of side $n$.

$33,65)$ and below $(n=3,9,17)$ this value. If this property is indeed a general property of habitat suitability, this analysis may yield an important guide for selecting the analysis scales to capture local (below break) and broad-scale (above break) properties of the terrain.

We also examined the global fractal dimension for bathymetric grids of the study area at different resolutions. For each grid cell size tested from $15 \mathrm{~m}$ to $325 \mathrm{~m}$ we found that the global fractal dimension only varied within the range of 2.14-2.16 and did not illustrate the same pattern we get from 'smoothed' bathymetry.

\section{Wavelet Terrain Analysis}

Figure 13 shows example terrain parameters derived using the wavelet method using a local and broad analysis scale. Like the GIS-based methods, the wavelet approach effectively allows us to capture different scale properties of the terrain for each parameter. For both slope and TRI, the variation associated with individual mounds is captured at small analysis scales (Figures 13a and 13c), while the larger analysis scale (Figures 13b and 13d) highlights properties associated with the larger features of the terrain. These initial results are encouraging for further development of this approach to terrain analysis. The approach offers an elegant and efficient means for computing these variables, particularly when working with large grids. For example, we found clear advantages in computation speed using the wavelet approach for analysis of our Macnas Mounds gridded bathymetry data. Multiscale slope, aspect, terrain ruggedness, and generalized bathymetry were obtained simultaneously with wavelet analysis in just a few seconds using a standard desktop PC. This compares favorably with the GIS-based analysis which, although quick for small window sizes, takes over a minute to calculate a single parameter using the larger analysis windows.

\section{Use of Terrain Variables for Habitat Suitability Modeling}

Our ecological niche factor analysis reveals that the squat lobster is quite restricted in terms of suitable habitat with a marginality value of 3.166 indicating a preference for areas differing from the average conditions within the study and a tolerance (1/specialisation) 
(a)

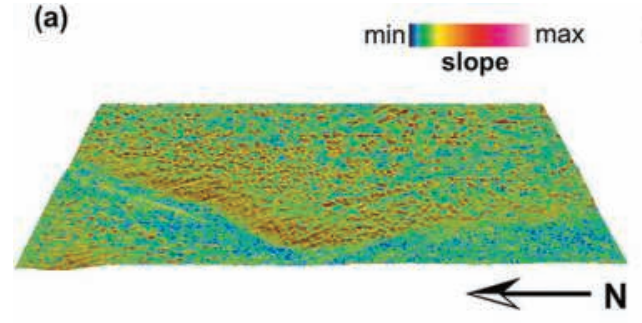

(c)

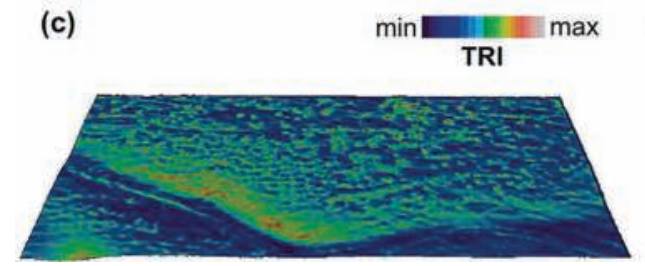

(b)

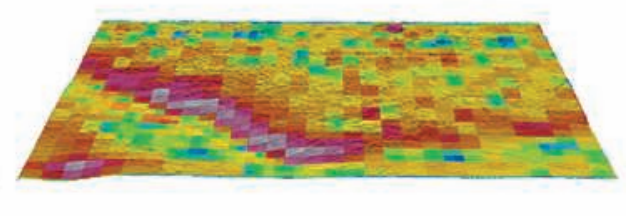

(d)
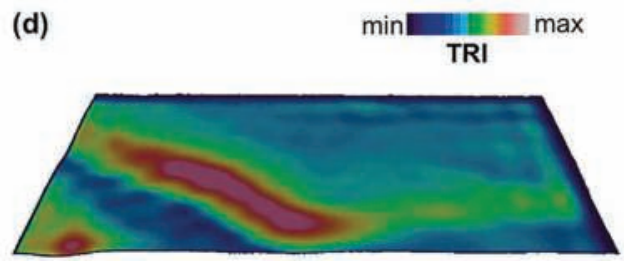

Figure 13. Three dimensional views of the Macnas Mounds area from west showing results of multi-scale terrain analysis using wavelets for (a, b) slopes and (c, d) TRI, at dyadic scales 4 and 32 (i.e. $60 \mathrm{~m}$ and $480 \mathrm{~m}$ ). Slopes were calculated using the techniques with the help of the wavelet toolbox in MATLAB. Since the wavelet used in the analysis corresponds to a larger ground area in (b) we observe a pixelated appearance in the shaded surface. TRI values were calculated based on the $n \times n$ version of the TRI equation. In order to demonstrate how we can obtain wavelet-based TRI values at each cell in the original grid, we have re-sampled the wavelet outputs to give the smooth shaded surfaces for both scales in (c, d).

value of 0.05 , indicating that this animal is quite restricted in the range of conditions it occupies. The EGVs were converted to a set of uncorrelated factors of which four were retained for the factor map computation. These four factors (selected by comparison with the broken stick distribution (Hirzel et al. 2002; MacArthur 1960)) account for $97 \%$ of the total information (100\% of the marginality and $95 \%$ of the specialization). The first factor alone accounts for $100 \%$ of the marginality and $42 \%$ of the specialization, while the remaining specialization is explained by the remaining factors. In Table 1 we can observe the contribution to each factor of the individual EGVs - the larger the absolute value the greater that variable's weight on that factor. We have highlighted the major contributors to the first factor, which is the most influential to our model. These tend to be those terrain variables that highlight the mound features including measures of curvature (particularly the smaller scale variables), BPI and fractal dimension. The second factor accounts for a large proportion $(30 \%)$ of the remaining specialization and includes bathymetry, orientation, and some of the larger-scale measures of curvature and BPI. Our model includes most of the calculated terrain variables as EGVs. However, we found that the model performed better without the inclusion of the largest scale variables $n=65$ which included large regions with little variation and therefore contribute little to the overall model. Larger scale terrain features such as the channel to the northwest of the study area are still highlighted by the $n=33$ variables; however, eastness (33) was also excluded on the basis of little variation.

Using these four factors, we successfully fitted a model using the harmonic mean algorithm. Our model (Figure 14) indicates that the most suitable habitat for squat lobsters is on the top of the mounds. The model performed convincingly during cross-validation. Area-adjusted frequency (AAF) scores for the high habitat suitability bins are well above those that could be generated by chance alone (mean AAF = 1), and the scores for the lowest bin are below 1, proving that between cross-validation runs we encounter few 
Table 1

Contribution of EGVs to factors generated by ENFA. Those EGVs making the largest contribution $(<-0.1$ or $>0.1)$ to each factor are highlighted bold. Note that for the first factor positive signs indicate a preference by the species for values above the mean for each EGV while negative values indicate a preference for values below the mean. For the remaining factors signs have no ecological relevance

\begin{tabular}{|c|c|c|c|c|}
\hline EGV & $\begin{array}{c}\text { Factor } 1 \\
\text { Marginalilty } \\
(100 \%) \\
\text { Specialization } \\
(42 \%)\end{array}$ & $\begin{array}{c}\text { Factor } 2 \\
\text { Specialization } \\
(30 \%)\end{array}$ & $\begin{array}{c}\text { Factors } \\
\text { Specialization } \\
(19 \%)\end{array}$ & $\begin{array}{c}\text { Factor } 4 \\
\text { Specialization } \\
(4 \%)\end{array}$ \\
\hline Bathymetry & 0.087 & -0.316 & 0.454 & $-\mathbf{0 . 3 3 7}$ \\
\hline Slope (3) & 0.092 & 0.02 & 0.006 & 0.003 \\
\hline Slope (9) & 0.013 & 0.00 & -0.004 & -0.032 \\
\hline Slope (17) & 0.033 & 0.007 & $-\mathbf{0 . 1 0 7}$ & -0.22 \\
\hline Slope (33) & 0.052 & 0.046 & -0.331 & 0.265 \\
\hline Northness (3) & 0.095 & 0.01 & 0.003 & -0.023 \\
\hline Northness (9) & 0.061 & -0.007 & -0.008 & -0.027 \\
\hline Northness (17) & 0.067 & -0.365 & -0.31 & -0.071 \\
\hline Northness (33) & -0.008 & 0.181 & -0.042 & -0.216 \\
\hline Easiness (3) & 0.063 & -0.006 & 0.021 & 0.006 \\
\hline Easiness (9) & -0.058 & 0.009 & 0.013 & -0.032 \\
\hline Plan curvature (3) & -0.128 & -0.017 & 0.003 & -0.004 \\
\hline Plan curvature (9) & -0.197 & 0.002 & 0.025 & 0.019 \\
\hline Plan curvature (17) & -0.082 & -0.072 & 0.046 & 0.174 \\
\hline Plan curvature (33) & 0.059 & 0.204 & 0.171 & -0.447 \\
\hline Profile curvature (3) & 0.139 & 0.009 & 0.004 & -0.008 \\
\hline Profile curvature (9) & 0.308 & -0.016 & -0.029 & -0.011 \\
\hline Profile curvature (17) & 0.183 & 0.076 & -0.087 & $-\mathbf{0 . 1 5 7}$ \\
\hline Profile curvature (33) & 0.142 & -0.125 & -0.108 & 0.124 \\
\hline Mean curvature (3) & 0.200 & -0.017 & -0.007 & 0.002 \\
\hline Mean curvature (9) & 0.323 & -0.002 & 0.069 & 0.081 \\
\hline Mean curvature (17) & 0.172 & -0.122 & 0.085 & 0.245 \\
\hline Mean curvature (33) & 0.055 & 0.093 & 0.055 & -0.21 \\
\hline $\mathrm{BPI}\langle 45\rangle$ & 0.267 & -0.007 & 0.004 & 0.036 \\
\hline $\mathrm{BPI}\langle 135\rangle$ & 0.321 & -0.081 & -0.221 & -0.126 \\
\hline BPI $\langle 255\rangle$ & 0.276 & 0.101 & 0.427 & -0.213 \\
\hline BPI $\langle 495\rangle$ & 0.240 & 0.445 & -0.336 & 0.211 \\
\hline BPI $\langle 975\rangle$ & 0.204 & -0.546 & 0.224 & 0.13 \\
\hline Rugosity & 0.212 & 0.007 & 0.012 & 0.011 \\
\hline TRI & 0.207 & 0.001 & -0.01 & 0.004 \\
\hline FD (9) & 0.063 & -0.013 & -0.027 & -0.045 \\
\hline FD (17) & 0.174 & -0.029 & -0.078 & -0.163 \\
\hline FD (33) & 0.160 & -0.031 & -0.135 & 0.033 \\
\hline $\mathrm{FD}(65)$ & 0.090 & 0.017 & -0.204 & 0.392 \\
\hline
\end{tabular}




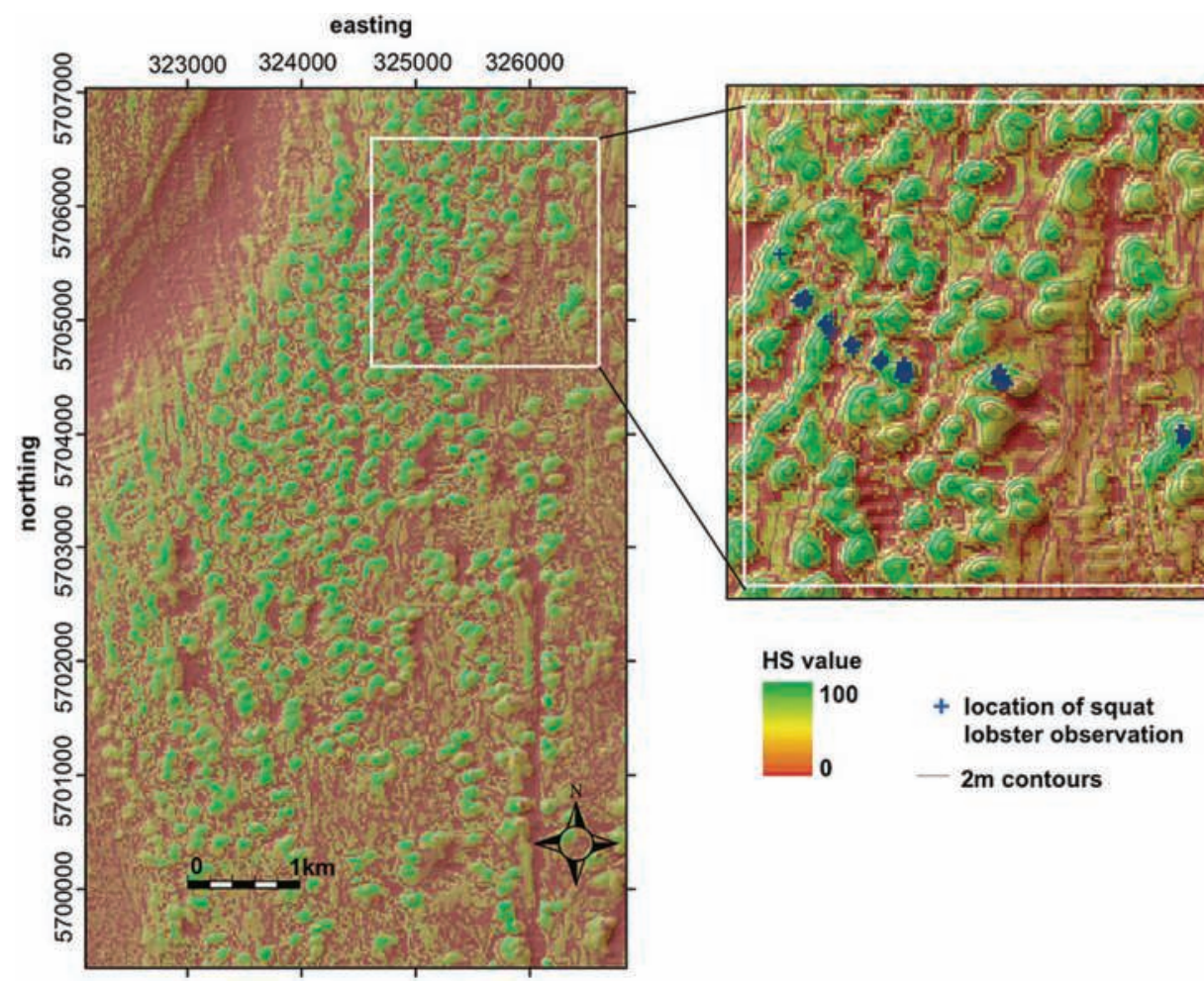

Figure 14. Predicted habitat suitability for squat lobsters in the Macnas Mounds study area based on multiscale, multiparameter terrain variables (Table 1). Habitat suitability (HS) calculated using ENFA in BioMapper 3.1 using the Harmonic Mean Algorithm. Grid cell size $15 \mathrm{~m}$. Projected coordinates UTM Zone 29 N (WGS84).

species observations at low HS scores rising to many species observations at high HS scores. This indicates good predictive power in terms of mean AAF score for the high HS bins, comparable with those indicated in other published studies using cross validation (e.g., Boyce et al. 2002; Hirzel and Arlettaz 2003). Our model does exhibit quite a range of variability among cross validation results, particularly for high HS bins. However, even the lower end of this range produces high scores for the area-adjusted frequency. The reason for this variability may be due to the relatively few observations across the study area, or may point to the fact that some other predictor variables should be included in the model (e.g., surficial geology, current velocities, water mass properties).

We compared the performance of our model containing multi-scale multi-parameter EGVs with those constructed using only EGVs from single scale analyses or single parameters. We performed cross validation on each of the models (Figure 15). Examination of the mean AAF scores across HS bins clearly indicates that the multi-scale, multiparameter model performs best. Although some of the models based on a subset of parameters performed reasonably well in cross validation, on looking at the visual representation of the results in our GIS, we have reservations about their predictions. For this dataset the analyses at an intermediate scale $n=17$ produced the best cross validation results using single scale variables, and visually the model output looks reasonable. We have greatest confidence in the multiscale model as it also includes all the small-scale terrain variability relevant to the species distribution. 
(a)

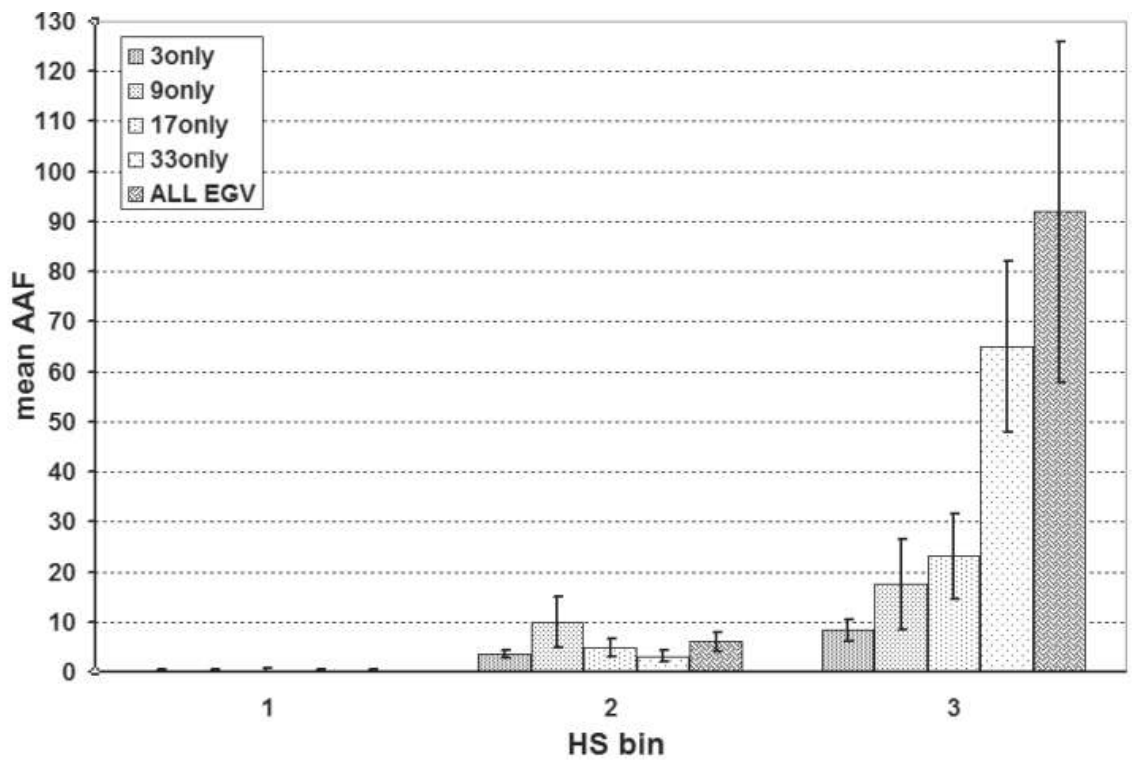

(b)

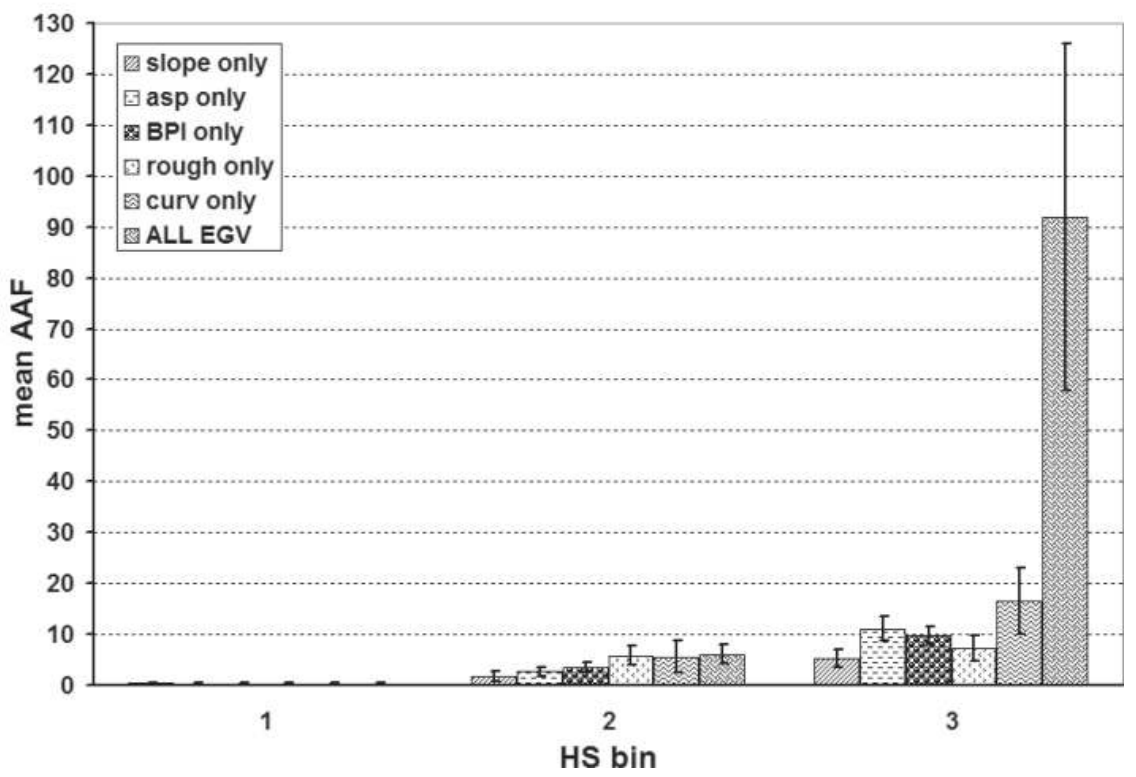

Figure 15. (a) Comparison of cross validation performance for multi-scale, multi-parameter HS model with single-scale, multi-parameter models. HS bin 1 (0-33), bin 2 (34-67), bin 3 (68-100). (b) Comparison of cross validation performance for multi-scale, multi-parameter HS model (ALL EGV) with multi-scale, single-parameter models. Note higher max AAF score obtained with model using all EGVs. 


\section{Discussion}

Terrain analysis of deep-water multibeam bathymetry will always be complicated by the fact that on the continental slope we obtain data at different resolutions. We have shown that a variety of methods exist for terrain analysis on these data and these have been successfully applied to the generation of a suite of quantitative descriptor variables of relevance to benthic habitat. In several cases (e.g., slope, curvature, roughness) we have highlighted the fact that several different methods exist for the calculation of nominally the same parameter or the same type of variable. The algorithm should be chosen with regard for the particular analysis required (Warren et al. 2004). We also have highlighted the use of methods such as curvature and fractal dimension, which have largely been overlooked in previous terrain analyses of multibeam data but may offer valuable additional information for habitat mapping and conservation. For example, although not based on multibeam data, a study by Schwinghamer et al. (1996) suggested that the fractal dimension of the seabed is reduced in areas that have been trawled.

Perhaps most importantly we have shown that the computation of these terrain variables needs not be restricted by grid-cell size to the immediate neighborhood surrounding each raster cell. By highlighting methods which facilitate multiscale analysis, we have shown how the analysis scale may be selected by the user, perhaps to delineate terrain features at a particular scale, or to match up the analysis scale with data gridded at a different resolution.

Extending the work of Lundblad et al. (2006), an integrated tool for performing BPI, rugosity and slope calculations and classifying benthic terrain in terms of these metrics has recently been developed as an ArcGIS extension by Rinehart et al. (2004). While this tool facilitates the computation of BPI at multiple scales the other terrain parameters are currently limited to single scale analysis. Increased awareness and availability of multi-scale methods should help promote their use in terrain analysis using bathymetric data for habitat mapping and related work. At present, it seems GIS-based methods are the most readily available to the scientific community. However, further development with wavelet methods may yield more efficient and flexible computation in the future.

Although we only had species observation data for a portion of the study area, the ENFA method successfully allowed us to produce HS maps on the basis of this information. Based on the maximum scores attained by the mean AAF values, our models appear to perform particularly well. However, we note comments by Hirzel et al. (2006) that the absolute values for mean AAF are influenced by the extent of the study relative to the species distribution and therefore may not be relevant when comparing models for different regions or species. Rather, the shape of the curve and variability among bins and cross validation results are more important for these purposes. In Figure 14 we presented our HS scores on a continuous scale; however, it may be more useful (Hirzel et al. 2006) to limit our classification to a few classes that are well defined by our model. This aspect of presentation and confidence in the product will become increasingly important as this type of predictive map gains attention for management and conservation beyond purely scientific circles.

We have clearly demonstrated that HS models based on a combination of terrain variables and scales perform better in cross validation and when assessed visually for their ecological relevance than those based on single parameters or scales. We note the limitations of our models in that we did not include other intermediate scales which may be just as important in determining faunal distribution. However, our results suggest that several spatial scales rather than any one scale are relevant to observed seabed habitat, and it is likely that the most relevant spatial scales will vary depending on the study 
area, bathymetric data, and fauna considered. There are also other environmental predictor variables (e.g., surficial geology, current velocities, water mass properties) which, where available, could be used in tandem with terrain variables to improve the precision of future models. Results from our initial models also indicate that there may be an upper limit to the scale of analysis that may be useful for modeling, or characterizing, terrain in a given study area. Further experience with HS models for other fauna in this area confirm that the ENFA technique is well matched to our requirements.

\section{Acknowledgements}

The Irish National Seabed Survey is managed by the Geological Survey of Ireland (GSI). The authors wish to thank the GSI for making the data available, to NUI, Galway for use in this study. We also extend our appreciation to all involved in the collection of ROV-video data used in this study during cruise CE0505 of the R. V. Celtic Explorer. We are grateful to Page Valentine and colleagues at the United States Geological Survey for providing the macro for calculation of the Terrain Ruggedness Index and for discussions in relation to its use. This research was funded under Cycle 3 of the Program for Research in Third Level Institutions by the Higher Education Authority of Ireland and administered by the Martin Ryan Institute in NUI, Galway. AJG is partially funded by the European Commission's Sixth Framework Programme HERMES project, EC contract no GOCE-CT-2005-511234 under the priority 'Sustainable Development, Global Change and Ecosystems.

\section{References}

Albani, M., B. Klinkenberg, D. W. Andison, and J. P. Kimmins. 2004. The choice of window size in approximating topographic surfaces from digital elevation models. International Journal of Geographical Information Science 18(6):577-593.

Basillais, E. 1997. Coral surfaces and fractal dimensions: a new method. Comptes Rendus de l'Academie des Sciences—Series III—Sciences de la Vie, 320(8):653-657.

Beck, M. W. 2000. Separating the elements of habitat structure: independent effects of habitat complexity and structural components on rocky intertidal gastropods. Journal of Experimental Marine Biology and Ecology 249(1):29-49.

Bekkby, T., L. Erikstad, V. Bakkestuen, and A. Bjørge. 2002. A Landscape Ecological Approach to Coastal Zone Applications. Sarsia 87(5):396-408.

Bekkby, T., L. Erikstad, O. Christensen, and O. Longva. 2005. Effekten av skala og kriterier for inndeling i marine substrattyper. Vann 1:35-43.

Billett, D. S. M. 1991. Deep-sea holothurians. Oceanography and Marine Biology Annual Review 29:259-317.

Boyce, M. S., P. R. Vernier, S. E. Nielsen, and F. K. A. Schmiegelow. 2002. Evaluating resource selection functions. Ecological Modelling 157:281-300.

Bradbury, R. H., and R. E. Reichelt. 1983. Fractal Dimension of a Coral Reef at Ecological Scales. Marine Ecology Progress Series 10:169-171.

Brotons, L., W. Thuiller, M. B. Araújo, and A. H. Hirzel. 2004. Presence-absence versus presence-only modelling methods for predicting bird habitat suitability. Ecography 27:437448.

Commito, J. A., and B. R. Rusignuolo. 2000. Structural complexity in mussel beds: the fractal geometry of surface topography. Journal of Experimental Marine Biology and Ecology 255(2):133-152. 
Csillag, F., and S. Kabos. 2002. Wavelets, boundaries and the spatial analysis of landscape pattern. Ecoscience 9(2):177-190.

Dartnell, P. 2000. Applying Remote Sensing Techniques to map Seafloor Geology/Habitat Relationships. Masters Thesis, San Francisco State University, pp. 108.

Dartnell, P. and J. V. Gardner. 2004. Predicted Seafloor Facies from Multibeam Bathymetry and Acoustic Backscatter Data, Central Santa Monica Bay, California. Photogrammetric Engineering \& Remote Sensing 70(9):1081.

De Mol, B., P. Van Rensbergen, S. Pillen, K. Van Herreweghe, D. Van Rooij, A. McDonnell, V. Huvenne, M. Ivanov, R. Swennen, and J. P. Henriet. 2002. Large deep-water coral banks in the Porcupine Basin, southwest of Ireland. Marine Geology 188(1-2):193-231.

Dettki, H., R. Löfstrand, and L. Edenius. 2003. Modeling habitat suitability for moose in coastal northern Sweden: empirical vs. process-oriented approaches. Ambio 32(8):549-556.

Díaz, J. V. M. 1999. Analysis of Multibeam Sonar Data for the Characterization of Seafloor Habitats. MEng Thesis, University of New Brunswick, pp. 153.

Džeroski, S., and D. Drumm. 2003. Using regression trees to identify the habitat preference of the sea cucumber (Holothuria leucospilota) on Rarotonga, Cook Islands. Ecological Modelling 170:219-226.

Engler, R., A. Guisan, and L. Rechsteiner. 2004. An improved approach for predicting the distribution of rare and endangered species from occurrence and pseudo-absence data. Journal of Applied Ecology 41:263-274.

Evans, I. S. 1980. An integrated system of terrain analysis and slope mapping. Zeitschrift für Geomorphologic Suppl-Bd 36:274-295.

Fisher, P., J. Wood, and T. Cheng. 2004. Where is Helvellyn? Fuzziness of multi-scale landscape morphometry. Transactions of the Institute of British Geographers 29(1):106-128.

Florinsky, I. V. 1998. Accuracy of local topographic variables derived from digital elevation models. International Journal of Geographical Information Science 12(1):47-61.

Franklin, J. 1995. Predictive vegetation mapping: geographic modeling of biospatial patterns in relation to environmental gradients. Progress in Physical Geography 19(4):474499.

Franklin, J., P. McCullough, and C. Gray. 2000. Terrain Variables Used for Predictive Mapping of Vegetation Communities in Southern California. In Terrain Analysis: Principles and Applications, J. P. Wilson and J. Gallant (eds.). New York: John Wiley \& Sons Inc., pp. 331353.

Gage, J. D., and P. A. Tyler. 1991. Deep-Sea Biology: A natural history of organisms at the deep-sea floor. Cambridge, UK: Cambridge University Press, pp. 504.

Gallant, J. C., and J. P. Wilson. 2000. Primary Topographic Attributes. In Terrain Analysis: Principles and Applications, J. P. Wilson and J. Gallant (eds.). New York: John Wiley \& Sons Inc., pp. 51-85.

GOTECH, 2002. Report of the Survey in Zone 3 of the Irish National Seabed Survey: Volume 1 -Describing the results and the methods used, The Geological Survey of Ireland.

Greene, H. G., M. M. Yoklavich, R. M. Starr, V. M. O'Connell, W. W. Wakefield, D. E. Sullivan, J. E. McRea Jr, and G. M. Cailliet. 1999. A classification scheme for deep seafloor habitats. Oceanologica Acta 22(6):663-678.

Grehan, A. J., V. Unnithan, and J. Opderbecke. 2005a. Fishing Impacts on Irish Deepwater Coral Reefs: Making a Case for Coral Conservation. In Benthic habitats and the effects of fishing, P. W. Barnes and J. P. Thomas (eds.). Bethesda, MD: American Fisheries Society Symposium 41 American Fisheries Society, pp. 819-832.

Grehan, A., M. Wilson, J. Guinan, J. Ullgren, J. Riordan, S. Rooney, F. Sacchetti, and Shipboard Party. 2005b. Ocean habitat mapping in the deep-waters off the west coast of Ireland using a Remotely Operated Vehicle. CE 0505 Cruise Report. Department of Earth and Ocean Sciences, NUI, Galway.

Guisan, A., and W. Thuiller. 2005. Predicting species distribution: offering more than simple habitat models. Ecology Letters 8(9):993-1009. 
Halley, J. M., S. Hartley, A. S. Kallimanis, W. E. Kunin, J. J. Lennon, and S. P Sgardelis. 2004. Uses and abuses of fractal methodology in ecology. Ecology Letters 7:254-271.

Hartley, S., W. E. Kunin, J. J. O. Lennon, and M. J. Pocock. 2004. Coherence and discontinuity in the scaling of species' distribution patterns. Proceedings of the Royal Society of London B 271:81-88.

Herzfeld, U. C., and C. Overbeck. 1999. Analysis and simulation of scale-dependent fractal surfaces with application to seafloor morphology. Computers \& Geosciences 25(9):979-1007.

Hirzel, A. H. 2001. When GIS come to life. Linking landscape- and population ecology for large population management modeling: the case of Ibex (Capra ibex) in Switzerland. Ph.D. Thesis, University of Lausanne.

Hirzel, A. H., and R. Arlettaz. 2003. Environmental-envelope based habitat-suitability models. In $1 s t$ Conference on Resource Selection by Animals, B. F. J. Manly (ed.). Laramie, WY: Omnipress.

Hirzel, A. H., J. D.C. Hausser, and N. Perrin. 2002. Ecological-Niche Factor Analysis: How to compute Habitat-Suitability Maps without absence data? Ecology 83(7):2027-2036.

Hirzel, A. H., G. L. Lay, V. Helfer, C. Randin, and A. Guisan. 2006. Evaluating the ability of habitat suitability models to predict species presences. Ecological Modelling 199:142-152.

Horn, B. K. P. 1981. Hill shading and the reflectance map. Proceedings of the IEEE 69(1):14-47.

Hughes Clarke, J. E. 2003. Dynamic motion residuals in swath sonar data: Ironing out the creases. International Hydrographic Review 4(1):6-23.

Iampietro, P. J., and R. G. Kvitek. 2002. Quantitative Seafloor Habitat Classification using GIS Terrain Analysis: Effects of Data Density, Resolution and Scale (Poster), Symposium on Effects of Fishing Activities on Benthic Habitats: Linking Geology, Biology, Socioeconomics, and Management, Tampa, FL.

Iampietro, P. J., E. Summers-Morris, and R. G. Kvitek. August 2004. Species-Specific Marine Habitat Maps from High-Resolution, Digital Hydrographic Data, 24th Annual ESRI User Conference. San Diego, CA: ESRI.

Jenness, J. 2002. Surface Areas and Ratios from Elevation Grid (surfgrids.avx) extension for ArcView 3.x-version 1.2. Jenness Enterprises. Available at http://www.jennessent.com/arcview/ grid_tools.htm.

Jenness, J. 2005. Directional Slope extension for ArcView 3.x. Jenness Enterprises. Available at: http://www.jennessent.com/arcview/dir_slopes.htm.

Jones, K. H. 1998. A comparison of two approaches to ranking algorithms used to compute hill slopes. GeoInformatica 2(3):235-256.

Keitt, T. H. 2000. Spectral representation of neutral landscapes. Landscape Ecology 15:479-493.

Keitt, T. H., and D. L. Urban. 2005. Scale-specific inference using wavelets. Ecology 86(9):24972504.

Kenny, A. J., I. Cato, M. Desprez, G. Fader, R. T. E. Schuttenhelm, and J. Side. 2003. An overview of seabed-mapping technologies in the context of marine habitat classification. ICES Journal of Marine Science 60(2):411-418.

Kienzle, S. 2004. The effect of DEM raster resolution on first order, second order and compound terrain derivatives. Transactions in GIS 8(1):83-111.

Klages, M., J. Thiede, and J. P. Foucher, (eds.). 2004. The Expedition ARKTIS XIX/3 of the Research Vessel POLARSTERN in 2003. Berichte zur Polar- und Meeresforschung, 488.

Kostylev, V. E., R. C. Courtney, G. Robert, and B. J. Todd. 2003. Stock evaluation of giant scallop (Placopecten magellanicus) using high-resolution acoustics for seabed mapping. Fisheries Research 60(2-3):479-492.

Kostylev, V. E., J. Erlandsson, M. Y. Ming, and G. A. Williams. 2005. The relative importance of habitat complexity and surface area in assessing biodiversity: Fractal application on rocky shores. Ecological Complexity 2(3):272-286.

Kostylev, V. E., B. J. Todd, G. B. J. Fader, R. C. Courtney, G. D. M. Cameron, and R. A. Pickrill. 2001. Benthic habitat mapping on the Scotian Shelf based on multibeam bathymetry, surficial geology and sea floor photographs. Marine Ecology Progress Series 219:121-137. 
Kumar, P., and E. Foufoula-Georgiou. 1997. Wavelet analysis for geophysical investigations. Reviews of Geophysics 35(4):385-412.

Le Danois, E. 1948. Les Profondeurs de la Mer. Payot, Paris, pp. 303.

Leverette, T. L., and A. Metaxas. 2005. Predicting habitat for two species of deep-water coral on the Canadian Atlantic continental shelf and slope. In Cold-Water Corals and Ecosystems, A. Freiwald and J. M. Roberts (eds.). Berlin: Springer-Verlag, pp. 467-479.

Lundblad, E., D. J. Wright, J. Miller, E. M. Larkin, R. Rinehart, D. F. Naar, B. T. Donahue, S. M. Anderson, and T. Battista. 2006. A Benthic Terrain Classification Scheme for American Samoa. Marine Geodesy 29(2):89-111.

MacArthur, R. H. 1960. On the Relative Abundance of Species. American Naturalist 94:25-36.

Mallat, S. 1999. A wavelet tour of signal processing. New York: Academic Press.

Mandelbrot. 1983. The Fractal Geometry of Nature. New York: W. H. Freeman and Company, pp. 468.

Mark, D. M. 1984. Fractal dimension of a coral reef at ecological scales: a discussion. Marine Ecology Progress Series 14:293-294.

Mark, D. M., and P. B. Aronson, 1984. Scale-Dependent fractal dimensions of topographic surfaces: An empirical investigation with applications in geomorphology and computer mapping. Mathematical Geology 16(7):671-683.

Misiti, M., Y. Misiti, G. Oppenheim, and J. Poggi. 2002. Wavelet Toolbox. Mathworks users guide, version 2.1.

Mohn, C., and A. Beckmann. 2002. Numerical studies on flow amplification at an isolated shelfbreak bank, with application to Porcupine Bank. Continental Shelf Research 22(9):13251338.

Parnum, I. M., P. J. W. Sibawessy, and A. N. Garilov. 2004. Identification of seafloor habitats in coastal shelf waters using a multibeam echosounder, Acoustics 2004, Gold Coast, Australia.

Patthey, P. 2003. Habitat and corridor selection of an expanding red deer (Cervus elaphus) population. Ph.D. Thesis, Universite de Lausanne, pp. 158.

Rex, M. A., R. J. Etter, and C. T. Stuart. 1997. Large-scale patterns of species diversity in the deep-sea benthos. In Marine Biodiversity: Patterns and Processes, Tickell, C., R. Ormond, J. D. Gage, and M. V. Angel (eds.). Cambridge, UK: Cambridge University Press, pp. 94-121.

Riemann-Zürneck, K. 1986. On the biogeography of the Southwest Atlantic with special reference to sea anemones (Coelenterata: Actiniaria). Helgoländer Meeresunters 40:91-149.

Riley, S. J., S. D. DeGloria, and R. Elliot. 1999. A terrain ruggedness index that quantifies topographic heterogeneity. Intermountain Journal of Sciences 5(1-4):23-27.

Rinehart, R., D. J. Wright, E. R. Lundblad, E. M. Larkin, J. Murphy, and L. Cary-Kothera. 2004. ArcGIS 8.x Benthic Terrain Modeler: Analysis in American Samoa. San Diego, CA: 24th Annual ESRI User Conference.

Riordan, J., E. Omerdic, and D. Toal. 2005. Implementation and Application of a Real-Time Sidescan Sonar Simulator, IEEE Oceans, Brest, France.

Roberts, J. M., D. Long, J. B. Wilson, P. B. Mortensen, and J. D. Gage, 2003. The cold-water coral Lophelia pertusa (Scleractinia) and enigmatic seabed mounds along the north-east Atlantic margin: are they related? Marine Pollution Bulletin 46:7-20.

Roberts, J. M., C. J. Brown, D. Long, and C. R. Bates. 2005. Acoustic mapping using a multibeam echosounder reveals cold-water coral reefs and surrounding habitats. Coral Reefs 24(4):654669.

Saunders, S. C., J. Chen, T. D. Drummer, E. J. Gustafson, and K. D. Brosofske. 2005. Identifying scales of pattern in ecological data: a comparison of lacunarity, spectral and wavelet analysis. Ecological Complexity 2:87-105.

Schmidt, J., I. S. Evans, and J. Brinkmann. 2003. Comparison of polynomial methods for land surface curvature calculation. International Journal of Geographical Information Science 17(8):797814. 
Schmidt, J., and A. Hewitt. 2004. Fuzzy land element classification from DTMs based on geometry and terrain position. Geoderma 121(3-4): 243-256.

Schwinghamer, P., J. Y. Guigné, and W. C. Siu. 1996. Quantifying the impact of trawling on benthic habitat structure using high resolution acoustics and chaos theory. Canadian Journal of Fisheries and Aquatic Sciences 53:288-296.

Shao, X., and C. Ma. 2003. A general approach to derivative calculation using wavelet transform. Chemometrics and Intelligent Laboratory Systems 69(1-2):157-165.

Shary, P. A., L. S. Sharaya, and A. V. Mitusov. 2002. Fundamental quantitative methods of land surface analysis. Geoderma 107:1-32.

Tate, N., and J. Wood. 2001. Fractals and Scale Dependencies in Topography. In Scale in Geographical Information Systems, N. Tate and P. Atkinson (eds.). New York: John Wiley \& Sons, pp. 3551.

Travis, M. R., G. H. Elsner, W. D. Iverson, and C. G. Johnson. 1975. VIEWIT computation of seen areas, slope and aspect for land use planning. PSW 11/1975, Pacific Southwest Forest and Range Experimental Station, Berkley, California, USA.

Turcotte, D. L. 1992. Fractals and chaos in geology and geophysics. Cambridge, UK: Cambridge University Press, 221 pp.

Valentine, P. C., S. J. Fuller, L. A. Scully. 2004. Terrain Ruggedness Analysis and Distribution of Boulder Ridges in the Stellwagen Bank National Marine Sanctuary Region (poster). Galway, Ireland: 5th International Symposium on Marine Geological and Biological Habitat Mapping (GeoHAB), May 2004.

Van De Beuque, S., J.-M. Auzende, Y. Lafoy, and R. Grandperrin. 1999. Benefits of swath mapping for the identification of marine habitats in the New Caledonia Economic Zone. Oceanologica Acta 22(6):641-650.

Wallace, J., B. Morris, and P. Howarth. 2004. The Effects of Scale on Fractal Dimension of Topography: A Case Study from Sudbury, Ontario, Canada, IGARSS '04-Geoscience \& Remote Sensing Symposium IEEE, pp. 2845-2845.

Warren, S. D., M. G. Hohmann, K. Auerswald, and H. Mitasova. 2004. An evaluation of methods to determine slope using digital elevation data. Catena 58:215-233.

Weiss, A. D. 2001. Topographic Positions and Landforms Analysis (poster), ESRI International User Conference, July 2001. San Diego, CA: ESRI.

Whitmire, C. E., W. W. Wakefield, R. W. Embley, S. G. Merle, B. N. Tissot, and N. Puniwai. 2004. Quantitative benthic habitat characterization at Heceta Bank, Oregon. The Journal of the Acoustical Society of America 116(4):2486-.

Wilbur, A. R. 2000. Fish habitat characterization and assessment: approach to integrate seafloor features and juvenile organisms data. Proceedings of the Oceans 2000 MTS/IEEE Conference and Exhibition, Providence, Rhode Island, USA. Volume 3:1555-1561.

Wilson, M. F. J. 2006. Deep sea habitat mapping using a remotely operated vehicle: Mapping and modeling seabed terrain and benthic habitat at multiple scales in the Porcupine Seabight, SW Ireland. Ph.D. Thesis, National University of Ireland, Galway. 266 pp.

With, K. A., and A. W. King. 1997. The use and misuse of neutral landscape models in ecology. Oikos 79:219-229.

Wood, J. 1996. The Geomorphological Characterisation of Digital Elevation Models. Ph.D. Thesis, University of Leicester.

Wood, J. 1998. Modeling the Continuity of Surface Form Using Digital Elevation Models. In Proceedings, 8th International Symposium on Spatial Data Handling, T. Poiker and N. Chrisman. (eds.). Vancouver, pp. 725-736.

Wood, J. 1999. Visualization of Scale Dependencies in Surface Models, International Cartographic Association Annual Conference, Ottawa, August 1999.

Wood, J. 2005. Landserf Version 2.2 (www.landserf.org).

$\mathrm{Wu}, \mathrm{X}$. B., and F. E. Smeins. 2000. Multiple-scale habitat modeling approach for rare plant conservation. Landscape and Urban Planning 51(1):11-28. 
Zaniewski, A. E., A. Lehmann, and J. M. Overton. 2002. Predicting species spatial distributions using presence-only data: a case study of native New Zealand ferns. Ecological Modelling 157: 261-280.

Zevenbergen, L. W., and C. Thorne. 1987. Quantitative analysis of land surface topography. Earth Surface Processes and Landforms 12:47-56.

Zhang, X., N. A. Drake, J. Wainwright, and M. Mulligan. 1999. Comparison of slope estimates from low resolution DEMS: Scaling issues and a fractal method for their solution. Earth Surface Processes and Landforms 24:763-779. 